Clinical practice guidelines for communicating prognosis and end-of-life issues with adults in the advanced stages of a life-limiting illness, and their caregivers

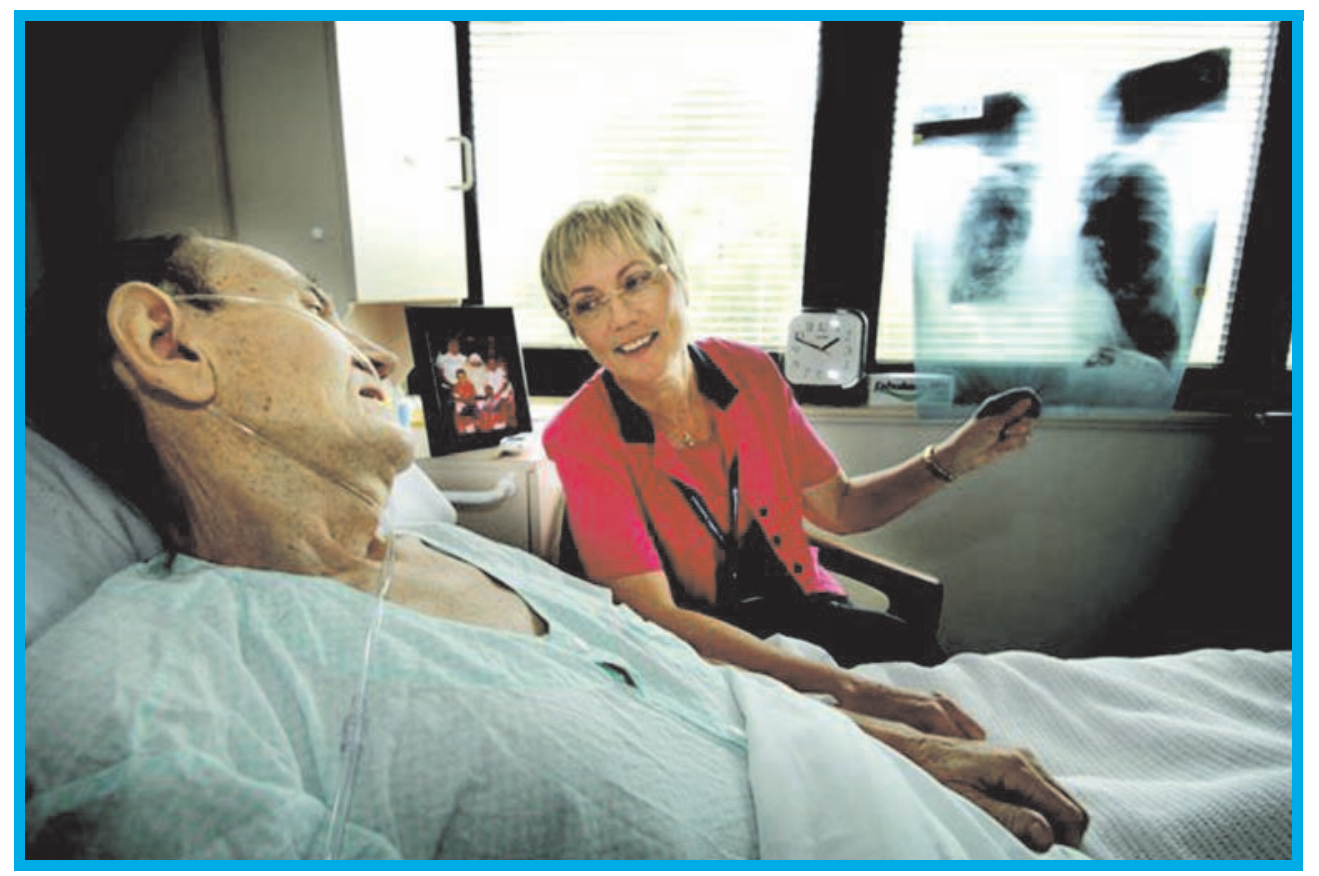




\title{
Clinical practice guidelines for communicating prognosis and end-of-life issues with adults in the advanced stages of a life-limiting illness, and their caregivers
}

\author{
Josephine M Clayton, Karen M Hancock, Phyllis N Butow, \\ Martin HN Tattersall and David C Currow
}

Development of these guidelines was supported by a Strategic Research Grant from the National Health and Medical Research Council on "Discussing prognosis and end-of-life issues in palliative care; current practice and development of an evidence based training program".

The Chief Investigator (Josephine Clayton) is supported by a Cancer Institute NSW Clinical Research Fellowship.

Cover photograph courtesy of The Australian newspaper, Lyndon Mechielsen. 


\title{
Contributors
}

\section{Writing committee}

\section{Dr Josephine M Clayton (Chair)}

Head of Department of Palliative Care, Royal North Shore Hospital, Sydney, NSW;

Senior Lecturer and Cancer Institute NSW Research Fellow, Faculty of Medicine, University of Sydney, Sydney, NSW.

Dr Karen M Hancock

Project Coordinator and Research Associate, Medical Psychology Research Unit, University of Sydney, Sydney, NSW.

\section{Professor Phyllis N Butow}

Professor of Psychology, University of Sydney, Sydney, NSW.

Professor Martin H N Tattersall

Professor of Cancer Medicine, University of Sydney, Sydney, NSW.

\section{Professor David C Currow}

Professor of Palliative and Supportive Care, Flinders University, Adelaide, SA.

Correspondence: jclayton@med.usyd.edu.au

\section{Australian and New Zealand Expert Advisory Group}

Dr Jonathan Adler, Palliative Care Physician • Professor Sanchia Aranda, Cancer Nursing

Dr Kirsten Auret, Palliative Care Physician • Dr Fran Boyle, Medical Oncologist $\bullet$ Dr Annette Britton, Geriatrician

Associate Professor Richard Chye, Palliative Care Physician • Dr Katy Clark, Palliative Care Physician

Associate Professor Patricia Davidson, Cardiac Nursing • Dr Jan Maree Davis, Palliative Care Physician

Professor Afaf Girgis, Behavioural Scientist • Dr Sara Graham, Carers NSW Representative/Advocate

Professor Janet Hardy, Palliative Care Physician • Ms Kate Introna, Palliative Care Nursing

Professor John Kearsley, Radiation Oncologist • Professor lan Kerridge, Ethicist and Haematologist

Professor Linda Kristjanson, Palliative Care Nursing • Dr Peter Martin, Palliative Care Physician

Dr Amanda McBride, General Practitioner $\bullet$ Ms Anne Meller, Aged Care Nursing

Associate Professor Geoffrey Mitchell, General Practitioner • Dr Alison Moore, Linguist

Ms Beverley Noble, Cancer Voices Consumer Representative $\bullet$ Professor lan Olver, Medical Oncologist

Ms Sharon Parker, Nursing, Clinical Trials Research - Associate Professor Matthew Peters, Respiratory Physician

Dr Peter Saul, Intensive Care Specialist • Associate Professor Cameron Stewart, Lawyer

Ms Lyn Swinburne, Breast Cancer Network Australia Consumer Representative $\bullet$ Dr Bernadette Tobin, Ethicist

Ms Kathryn Tuckwell, Linguist $\bullet$ Professor Patsy Yates, Palliative Care Nursing

\section{Endorsing organisations}

\author{
Australasian Society of HIV Medicine \\ Australian and New Zealand Society of Palliative Medicine \\ Australasian Chapter of Palliative Medicine, Royal Australasian College of Physicians \\ Australian College of Rural and Remote Medicine \\ Australian General Practice Network \\ Australian Society of Geriatric Medicine \\ Cancer Voices Australia \\ Cardiac Society of Australia and New Zealand \\ Clinical Oncological Society of Australia \\ Motor Neurone Disease Association of Australia \\ Palliative Care Australia \\ Palliative Care Nurses Australia \\ Royal Australian College of General Practitioners \\ Royal College of Nursing, Australia \\ Thoracic Society of Australia and New Zealand
}

MJA • Volume 186 Number 12 • 18 June 2007 


\section{Contents}

Summary

Guideline development and use ................................ S85

Methods of guideline development. ............................ 885

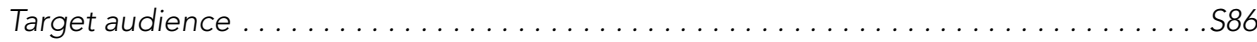

How to use the guidelines................................... 886

Grading of recommendations.................................... 886

Limitations of the guidelines................................... 886

The guidelines . . . . . . . . . . . . . . . . . . . . . . . . . . . . . . . S87

Timing of prognostic and end-of-life discussions . . . . . . . . . . . . . . . . . . . . . . S87

Preparation for the discussion. . . . . . . . . . . . . . . . . . . . . . . S87

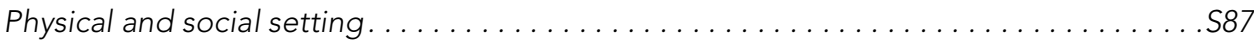

How to discuss prognosis and end-of-life issues....................... 888

General strategies to facilitate hope and coping when discussing

prognosis and end-of-life issues.................................592

Additional background information about specific content areas and issues . . ......S93

Role of self-care .............................................S103

References ................................................... S105 


\section{CLINICAL PRACTICE GUIDELINES}

\section{Summary}

Prognostic and end-of-life communication is a vital skill for health care professionals caring for patients with progressive life-limiting illnesses, and their families. Expert opinion varies, and highquality evidence on how best to discuss these issues with such patients and their caregivers is limited. These guidelines were developed to address these issues. The guidelines were developed through the following methods:

- Systematic literature review of the best available evidence on discussion of prognosis and end-of-life issues;

- Review of previous relevant guidelines and expert opinions in the literature; and

- Refining of draft guidelines by an expert advisory panel.

The key recommendations of these guidelines are for health professionals to consider the recommendations conveyed by the acronym PREPARED.

Prepare for the discussion, where possible:

- Confirm pathological diagnosis and investigation results before initiating discussion.

- Try to ensure privacy and uninterrupted time for discussion.

- Negotiate who should be present during the discussion. Relate to the person:

- Develop rapport.

- Show empathy, care and compassion during the entire consultation.

Elicit patient and caregiver preferences:

- Identify the reason for this consultation and elicit the patient's expectations.

- Clarify the patient's or caregiver's understanding of their situation, and establish how much detail and what they want to know.

- Consider cultural and contextual factors influencing information preferences.

Provide information, tailored to the individual needs of both patients and their families:

- Offer to discuss what to expect, in a sensitive manner, giving the patient the option not to discuss it.

- Pace information to the patient's information preferences, understanding and circumstances.

- Use clear, jargon-free, understandable language.
- Explain the uncertainty, limitations and unreliability of prognostic and end-of-life information.

- Avoid being too exact with timeframes unless in the last few days.

- Consider the caregiver's distinct information needs, which may require a separate meeting with the caregiver (provided the patient, if mentally competent, gives consent).

- Try to ensure consistency of information and approach provided to different family members and the patient and from different clinical team members.

Acknowledge emotions and concerns:

- Explore and acknowledge the patient's and caregiver's fears and concerns and their emotional reaction to the discussion.

- Respond to the patient's or caregiver's distress regarding the discussion, where applicable.

(Foster) Realistic hope:

- Be honest without being blunt or giving more detailed information than desired by the patient.

- Do not give misleading or false information to try to positively influence a patient's hope.

- Reassure that support, treatments and resources are available to control pain and other symptoms, but avoid premature reassurance.

- Explore and facilitate realistic goals and wishes, and ways of coping on a day-to-day basis, where appropriate.

Encourage questions and further discussions:

- Encourage questions and information clarification; be prepared to repeat explanations.

- Check understanding of what has been discussed and if the information provided meets the patient's and caregiver's needs.

- Leave the door open for topics to be discussed again in the future.

Document:

- Write a summary of what has been discussed in the medical record.

- Speak or write to other key health care providers involved in the patient's care. As a minimum, this should include the patient's general practitioner. 


\section{Guideline development and use}

Discussing prognosis and end-of-life issues has been identified as an important component of care by patients with progressive lifelimiting illnesses, and their families. ${ }^{1,2}$ Being adequately informed is essential for such patients and their caregivers to participate in decisions about their treatment and care, to set goals and priorities, and to prepare for death. Clinicians need to provide information in a way that assists patients and their families to make appropriate decisions, be informed to the level that they wish, and cope with their situation. These guidelines have been prepared to assist clinicians with this difficult but important task.

\section{Methods of guideline development}

The guidelines were developed using the following process:

- Literature review:

> systematic review of the best available evidence regarding discussion of prognosis and end-of-life issues with patients with a progressive life-limiting illness, and their caregivers; and

$>$ review of previous related guidelines and expert opinions.

- Refining of guidelines with an expert advisory panel.

\section{Literature review}

\section{Systematic review}

The systematic review ${ }^{3}$ was conducted in conjunction with personnel of the systematic review section of the National Health and Medical Research Council (NHMRC) Clinical Trials Centre, in accordance with the principles and processes recommended by the Cochrane Review. ${ }^{4}$ Eligible studies were those that sampled adult patients who had an advanced progressive life-limiting illness with less than 2 years to live, including but not restricted to cancer, endstage pulmonary disease, end-stage cardiac failure, and motor neurone disease; and/or the caregivers (including bereaved relatives) of such patients; and qualified health care professionals. More specifically for studies where patients formed the study group, the eligibility criteria included: patients in specialist palliative care or hospice settings (inpatient or community), and patients in any care setting with a diagnosis of an advanced lifelimiting illness being treated with palliative intent and with a life expectancy of less than 2 years. Where samples were mixed (ie, potentially curable and advanced disease), studies were included if more than $50 \%$ of patients had an advanced life-limiting illness or where the results for such patients were provided separately. Studies where patients formed the study group were excluded if they involved patients with chronic diseases with likely life expectancy of greater than 2 years (such as dementia and multiple sclerosis), patients being treated with curative intent, or patients being cared for in an intensive care unit, or if it was not possible to determine what percentage of the study group was being treated with palliative intent or had a life expectancy of less than 2 years.

The medical literature was searched to identify relevant studies and reviews for the period between 1966 and November 2004. Searches were conducted via MEDLINE, CINAHL, EMBASE, Psycinfo and the Cochrane Register of Controlled trials (Central). Out of 4167 abstracts retrieved by electronic searches, and a further 127 abstracts identified by hand searching, 278 full manuscripts were considered for inclusion in the review. One hundred and fifty-one did not meet the eligibility criteria and four were duplicates; hence, 123 articles were included. Individual reviewers extracted data from each study using a standard format. Data extraction was checked by a second reviewer for $10 \%$ of studies to ensure consistency.

Most studies were descriptive, examining provider practices and patient and/or caregiver views, attitudes, knowledge and behaviour (Level IVa evidence according to the NHMRC 1995 ratings $^{5}$ ). Such studies are not considered admissible evidence in the more recent NMHRC rating scale. ${ }^{6}$ These NHMRC rating scales are designed for research questions regarding interventions, diagnosis, aetiology, screening and prognostic factors, but are not readily applicable to the topic of these guidelines.

\section{Review of consensus guidelines and expert opinion}

Relevant consensus guidelines and expert opinion were incorporated into the guidelines because of the lack of evidence for some topics. Consensus guidelines in similar areas were retrieved via hand searching and the search strategy for the systematic review. They were excluded from the systematic review because they were not studies. These guidelines included areas such as breaking bad news $(n=2)$, psychosocial clinical practice guidelines for women with breast cancer $(n=1)$, clinical practice guidelines for advanced breast cancer $(n=1)$, therapeutic guidelines for palliative care $(n=1)$, advance directives $(n=1)$ and end-of-life care $(n=1)$. These guidelines used a rigorous consensus-building process, with many commissioned by the Australian or New South Wales Government and endorsed by national peak bodies. Published expert opinion - the considered opinion of clinical experts $(n=12)$ regarding communication of prognosis and end-of-life issues with patients, and their families, with advanced life-limiting illnesses — was reviewed and cited for areas where there was a lack of studies or consensus.

\section{Expert advisory panel}

An expert panel was convened, comprising 35 Australian and New Zealand health care professionals and consumers (nine palliative care medical specialists, three medical oncologists, three palliative care nurses, three consumers [including two cancer patients and one caregiver], two general practitioners, two psychosocial experts, two ethicists, two linguists, one oncology nurse, one cardiology nurse, one aged care nurse, one research nurse, one geriatrician, one respiratory physician, one radiation oncologist, one intensive care specialist, and one lawyer). The panel members were selected to reflect the multidisciplinary nature of care for patients with advanced progressive life-limiting illnesses. Representatives were selected on the basis of either their clinical expertise or a track record of publications on this topic. Consumer bodies, such as Carers NSW and Cancer Voices NSW, were approached and provided consumer representation. The guidelines were refined with the assistance of this expert panel using consensus methods (modified nominal group technique/Delphi method ${ }^{7}$ ).

This group was sent the guidelines by mail and asked to evaluate them (both by rating each individual point using a nominal scale and by providing suggested word changes and comments following critical review). The group then had a face-to-face meeting and discussed discrepancies of opinion and all items rated by at least 


\section{CLINICAL PRACTICE GUIDELINES}

$10 \%$ of the panel to be either "not important" or "somewhat important" (a score of 1 or 2 on a five-point scale where 3 was "important" and 5 was "essential"). Following the meeting, the research team refined the guidelines based on the recommendations of the expert panel. The final draft was sent again to the expert panel for a further round of feedback and final approval.

\section{Target audience}

These guidelines were developed for use by all members of the health care team involved in the care of patients with progressive life-limiting illnesses, and their families, including GPs, specialist doctors and trainees (including palliative care, medical and radiation oncology, surgical oncology, geriatrics, haematology, respiratory medicine, cardiology, and neurology), junior medical staff, nurses, social workers, psychologists, psychiatrists, physiotherapists and occupational therapists. Some health care professionals (such as junior medical staff, generalist nurses and some allied health staff) may not feel it is their role to be giving detailed prognostic or end-of-life information to patients. However, the general principles in these guidelines are relevant for all health care professionals interacting with this patient population and their families at home or in hospital.

\section{How to use the guidelines}

Discussions about prognosis and end-of-life issues can be conceptualised as a process of ongoing conversation over time, rather than a single discussion. ${ }^{8}$ Hence, the material in these guidelines is best covered with patients and caregivers over multiple consultations, depending on the clinical circumstances and information needs of the patient and caregivers. The response of patients and their caregivers will dictate the pace and volume of material to be discussed. Some of the issues (eg, likely symptoms and how they are treated, what will happen close to death) will be covered in different ways, or not at all, in the initial conversation compared with when the symptoms start appearing or accelerating. In the first instance, they can be discussed in general terms, and later in specific terms. It is important to give the patient and family an opportunity to have their information needs met regarding these topics, but at the same time to prevent overloading the patient and caregiver both informationally and emotionally.

The guidelines assume a relatively high level of knowledge, generic communication skills, and judgement. Maximum benefit in applying the guidelines by trainees or junior health care professionals may be facilitated by attending a basic communications skills workshop. ${ }^{9}$

Background information regarding some recommendations in the guidelines is given in the text. The recommendations themselves are presented in Boxes 1 to 16. Boxes 1 to 5 are relevant to all discussions of prognosis and end-of-life issues, and address the following topics: timing of the discussion, preparation for the discussion, physical and social setting, how to discuss prognosis and end-of-life issues, and general strategies to facilitate hope and coping. Boxes 6 to 16 are specific to certain content areas or issues. Useful phrases are given where applicable. It is suggested that you choose a phrase that fits your style and with which you feel comfortable. Some of the phrases can be adapted for your own use.

\section{Grading of recommendations}

The recommendations detailed in Boxes 1 to 16 are graded as follows:

DS = descriptive study or studies;

$\mathrm{CG}=$ existing consensus guidelines;

$\mathrm{EO}=$ published expert opinion; and

$\mathrm{RGP}=$ recommended good practice based on the clinical and consumer consensus opinion of the expert advisory group and chief investigators.

\section{Limitations of the guidelines}

The systematic literature review which informed these guidelines was limited to studies of patients, and/or their caregivers, with a known progressive life-limiting illness. The recommendations or suggested phrases may not be applicable to patients with debilitating chronic illnesses with a life expectancy of more than 2 years, patients having treatment with curative intent, and those in whom intensive care treatment would still have a reasonable chance of being effective. Likewise, end-of-life discussions with well elderly people, those in aged care facilities with uncertain disease trajectories, and patients in the early stages of dementia are beyond the scope of these guidelines.

All the articles included in the systematic review were written in English, and most of the patient and caregiver participants were from Anglo-Saxon backgrounds. Hence, some caution is required when interpreting these guidelines for patients from non-AngloSaxon backgrounds. 


\section{The guidelines}

Discussing prognosis and end-of-life issues is difficult. Research has identified deficiencies in communication between health care professionals and patients regarding prognosis and end-of-life issues. ${ }^{10}$ Many health care professionals are uncomfortable discussing these topics. ${ }^{11,12}$ Reasons include perceived lack of training, stress, no time to attend to the patient's emotional needs, fear of upsetting the patient, and a feeling of inadequacy or hopelessness regarding the unavailability of further curative treatment. ${ }^{13-17}$ Such avoidance can lead to poorer patient satisfaction and psychological morbidity. ${ }^{18,19}$ If information provision is not honest and detailed, patients may perceive that health care professionals are withholding potentially frightening information. ${ }^{20,21}$ When cancer patients are not adequately informed of their prognosis, they are more likely to choose aggressive anticancer treatments ${ }^{22}$ and make decisions that they later regret. ${ }^{23}$ Therefore, it is in the patient's best interests to offer such information rather than withhold it in an attempt to protect the patient from losing hope or being upset. Although many health care professionals believe introducing the topic will unnecessarily upset the patient and dispel any hope, evidence suggests that patients can engage in such discussions with minimal stress ${ }^{24}$ and maintain a sense of hope even when the prognosis is poor. ${ }^{8}$ In addition, awareness of prognosis is associated with greater satisfaction with care and lower depression levels in patients. ${ }^{18,19}$

\section{Timing of prognostic and end-of-life discussions (Box 1)}

Most patients from Western countries prefer some information regarding prognosis when first diagnosed with a life-limiting illness. ${ }^{25,30,31}$ However, this information can be difficult to comprehend at this time, ${ }^{32}$ and one study indicated that patients found the information distressing if they had not asked for it. ${ }^{25}$ In one study, most palliative care patient and caregiver participants felt that it was appropriate and important for the doctor or nurse to make this an accessible topic, because they may find it difficult to raise it themselves. ${ }^{15}$ Box 1 gives recommendations for when the health care professional should consider raising the topic, apart from when the patient initiates the discussion (eg, by asking a question).

\section{Preparation for the discussion (Box 2)}

If the consultation is planned, it is important to provide consistent, accurate information by reading clinical records, speaking with health care professionals, and researching the literature to obtain up-to-date knowledge. ${ }^{17,28,33-35}$ It is helpful for health care professionals to be aware of their own feelings of grief, anxiety or guilt (including fears about holding the discussion), particularly if they have known the patient for some time. These are normal responses, and self-acknowledgement may avoid projecting feelings or biases onto the patient or caregiver. ${ }^{36}$

\section{Physical and social setting (Box 3)}

\section{Relationship between the health care professional and patient or caregiver}

Good interaction between the patient and health care professional is fundamental to effective communication, ${ }^{43}$ and patients facing a progressive life-limiting illness place great emphasis on the relationship with their health care professional. ${ }^{2}$ Most patients prefer the information to come from a confident expert (ie, not delegated to the most junior person on the team). 1,25,37-40,44 While having a long-term relationship is important for many patients in discussing prognostic and endof-life issues, even the first consultation may be a time when some issues can be comfortably explored. ${ }^{15,35,38,45}$

\section{Who else should be present during the discussion}

Although it may be beneficial to provide support and ensure continuity of care by having another health care professional present, ${ }^{37,44,46}$ some patients are not in favour of this approach. ${ }^{31}$ Some research suggests that some patients wish to receive information from a different health care professional or another person (eg, priest), ${ }^{15}$ indicating that the health care professional needs to negotiate who delivers the information. Most but not all patients want to have a family member or friend with them. ${ }^{25,34,35}$ This should be ascertained.

\section{Timing of discussion}

Recommendation

- All patients with advanced progressive life-limiting illnesses should be given the opportunity to discuss prognosis (including DS ${ }^{15}$ life expectancy, how the illness may progress, future symptoms and effect on function) and end-of-life issues.

- Do not assume that the patient does not want to discuss the topic simply because he or she does not raise the issue, or because of cultural background.

- Give the patient the option not to discuss it or defer the discussion to a later time.

- Consider raising/introducing the topic in the following circumstances:

$>$ With all patients and their caregivers once it is clear that the patient has a life-limiting advanced progressive illness; or if the DS 25,26 doctor would not be surprised if the patient died within 6-12 months

$>$ When there is a change in condition, or a perception (by patients, caregivers or clinical staff) of change

$\mathrm{DS}^{27-29}$

$>$ When a treatment decision needs to be made

$\mathrm{DS}^{27}$

$>$ If there are requests or expectations that are inconsistent with clinical judgement

$\operatorname{DS}^{15,27,29}$

$>$ If disease-specific treatment is not working or there are complications from this treatment that limit its effectiveness

$>$ At the time of referring the patient to specialist palliative care services. 


\section{Preparation for the discussion}

Recommendation

Evidence level

- Ensure facts about the patient's clinical circumstances are correct.

- Before seeing the patient, read the clinical records and/or speak with relevant health care professionals to determine the patient's extent of disease and relevant comorbidities, and gain up-to-date knowledge about the patient's underlying illness and appropriate treatment options.

- Find out what the patient has been told by other health care professionals in order to provide consistent information (where appropriate). For example, speak with the referring specialist or general practitioner, have a case conference if required.

- Mentally prepare.

RGP

- Allow yourself time to confer with a colleague if the ensuing discussion is troubling you.

DS $^{15}$

RGP

\section{How to discuss prognosis and end-of-life issues (Box 4)}

\section{Importance of generic communication skills}

Trust can be built by using an empathic, patient-centred style. ${ }^{41}$ Good generic communication skills involve using eye contact (if culturally appropriate); using appropriate body language such as an open posture; sitting close to the patient; active listening such as nodding or making noises of agreement or encouragement to indicate understanding; reflecting empathically; and showing compassion by using a warm, caring, and respectful manner. ${ }^{1,2,25,37,39,44,47,49}$ An empathic, patient-centred style also involves using open-ended questions with an emotional content. This approach has been shown to elicit greater expression of feelings compared with the use of closed questions. ${ }^{71}$ These open-ended questions can be asked before discussing prognosis, palliative care or end-of-life issues so that the patient's concerns, goals and values can be determined. ${ }^{72}$ It can also help create an atmosphere where the patient is treated as a "whole person" (as well as the family) and feels that the health care professional is interested in and sensitive to their problems and feelings. ${ }^{73}$

\section{Clarifying patient and caregiver understanding}

Establishing the patient's and caregiver's understanding of the situation helps establish a common ground from which to start the discussion. ${ }^{74}$ In initial consultations, the health care professional

\section{Physical and social setting}

\section{Recommendation}

- If possible, ensure privacy, quiet (limit interruptions from pagers or telephones), and timing convenient for patient and health care professional.

- Ask the patient if he or she would like any family members or caregivers to be present during the discussion, especially if planned (eg, follow-up appointment after test results).

- If possible, ensure the health care professional leading the discussion is senior enough to be able to answer the patient's and caregiver's questions appropriately (ie, not the most junior person on the team).

- If a junior health care professional is required to do this task (ie, in an emergency clinical situation), it will be important to tell the patient or family what senior staff have been involved in discussions to date and when they will be available.

- Build trust and respect by using an empathic, patient-centred style (Box 4).

- Check that the patient is comfortable with additional health care professionals being present for the discussion if it is feasible and important for provision of ongoing care (eg, nurse, registrar).

- Ensure enough time is allocated to answer questions or repeat information not understood.

- If time is not available, allocate a date in the near future, and set limits at the beginning of the consultation.

- Optimise any communication aids as required (eg, use of interpreters or hearing aids where applicable) and ensure the patient is mentally capable of taking part in the discussion (eg, not confused).
Useful phrases (where applicable)

Evidence level

"Some people like to bring someone who is close DS $15,25,33,34$ to them to the appointment."

"Is there anyone else you would like to be here with you while we talk?"

"If there are things that you might prefer to discuss with me alone l'd be happy to organise that."

DS $^{1,25,35,37-40}$
RGP
EO $^{41}$

If planning a discussion: "Are you comfortable having another member of my team present when we discuss your results?"

"I would be very happy to discuss ... with you. We DS 2,25,42 won't have enough time today to address that properly. Is it all right if I come back [state when]?" 


\section{How to discuss prognosis and end-of-life issues}

Recommendation

- Use good generic communications skills and establish rapport with the patient and family.

- Make eye contact (if culturally appropriate), sit close to the patient, use appropriate body language, allow silence and time for the patient to express feelings.

- Engage in active listening (eg, attend to the patient fully, reflect what you think he or she has said).

- Show interest in the patient as an individual and as a whole person, as well as the family.

- Show compassion and use a warm, caring, respectful and empathic manner.

- Be willing to initiate and engage in conversations about what may happen in the future and dying.

- Ensure the patient and caregiver are aware that they can openly discuss these topics with you or someone else in the health care team if they wish.

- Broach the topic in a culturally appropriate and sensitive manner.

- Always give the patient and caregiver the option not to discuss these topics or to defer the discussion to another time.

- If the patient does not currently wish to discuss these topics, raise them again when the person's condition or situation changes (Box 1).

- Before giving new information, use open directive questions to clarify the patient's or caregiver's level of understanding of the illness.

- Consider asking the patient and caregiver what they have been told by other health care professionals and what information they have obtained from other sources (eg, Internet).

- If the discussion is prompted by a patient or caregiver question, consider:

$>$ Clarifying what they are asking and what motivated the question

Asking them what they think is the answer first.

- Elicit and clarify the patient's concerns, expectations and fears about the future, relevant to issues being discussed.

- Clarify what the patient wants to know and the level of detail preferred before giving new information.
Useful phrases (where applicable)

Evidence level

$\mathrm{DS}^{2,8,39,47}$

"If I've heard you right, you seem to be saying..."

$\mathrm{DS}^{1,2,39}$

$\operatorname{DS}^{15,31,39,48}$

"This has been a tough time for you and your family, and you

$\mathrm{DS}^{25,49}$ have faced the challenges of this illness with great courage."

"Do you have any questions or other concerns?"

$\operatorname{DS}^{1,2,28}$

"Some people are worried about things that may or may not happen in the future. It can help to talk about this."

"I am very happy to talk to you about any concerns or questions you have about this now or later. Is there anything you would like to ask me today about this?"

"Often people with conditions like yours have got a lot of questions that are sometimes scary, or sometimes they're not certain if they want to know the answer. Often the thing they fear or believe is worse than how it really is. So if there's anything you want to know, feel free to ask me and I'll answer as best as I can."

"What is your understanding of your health situation and what is likely to happen?"

"Do you have thoughts about where things are going with your illness?"

"Can you summarise to me what the doctors have explained to you about your illness? Do you think, or did they mention, the illness may affect your health in the future?"

"I am very happy to answer that, but do you mind telling me what made you ask that question?"

"What are you expecting to happen?"50

$\operatorname{DS}^{15,25,35,45}$

"What worries you most about ... [eg, what may happen]?"

"What frightens you about all of this?"

"What do you hope for the future?"

"What is your biggest concern at the moment?"

"How much would you like to know?"

$\operatorname{DS}^{15,25,35}$

"Some people like to know everything that is going on with them and what may happen in the future, others prefer not to know too many details. What do you prefer?"

"I am happy to give you as much information as I can based on what you want to know."

"What types of information would you like?"

(continued on page S90)

could elicit patient understanding when obtaining the patient's illness history (eg, by allowing them to tell their story and asking focussed or open-directive questions to clarify certain points). ${ }^{73}$ When the patient is well known to the health care professional, it may be more appropriate to consider summarising what has happened with their illness so far, before moving on to the current situation and clarifying the patient's understanding.

\section{Clarifying information needs}

There is evidence that doctors are not good at predicting patients' information preferences, and tend to underestimate patients' need for information. ${ }^{75-77}$ Doctors frequently perceive that the patient has a greater awareness or understanding than the patient reports. ${ }^{22,77-81}$ Patients with cancer and other life-limiting illnesses frequently have misunderstandings about their illness, prognosis 


\section{CLINICAL PRACTICE GUIDELINES}

\section{How to discuss prognosis and end-of-life issues (continued from page S89)}

\section{Recommendation}

- Clarify the caregiver's information needs (provided the patient gives consent to discuss the illness with the caregiver), as they may differ from the patient's needs.

- Be aware of cultural differences in information preferences and attitudes to discussing prognosis and dying.

- Clarify with the patient and family their cultural background or norms.

- Do not make assumptions about information needs based on the individual's cultural background or demographic information, but clarify with the individual and family.

- Regardless of the content of the prognostic or end-of-life discussion, explain the uncertainty and unreliability of prognostic predictions.

- Consider acknowledging the difficulty in living with this uncertainty.

- Tailor the information given according to the patient's or caregiver's level of understanding, concerns and information needs.

- The discussion may involve correcting misunderstandings regarding information obtained from other sources (eg, media or Internet).

- Give information in small chunks, at the person's pace.

- Check that the patient or caregiver has fully understood what has just been said.

- Use appropriate language: use everyday terms, straightforward and clear language, and unambiguous words; avoid euphemisms or jargon that could easily confuse, overwhelm and mask the true meaning of the message.

- Use the words "death" and "dying" where appropriate.

- Provide honest and realistic information in a straightforward manner.

- Avoid being blunt or giving more detailed information than desired by patients or caregivers.
Useful phrases (where applicable)

Evidence level

To patient:

$\mathrm{DS}^{25,52,53}$

"It is also important for [name of caregiver] to have the opportunity to find out the things [he/she] needs to know to be able to take care of you. Are you happy for me to speak with [him/her] about your medical condition?"

"Is it OK with you if I tell your [relative/caregiver] what I've discussed with you?"

"Often [daughters/sons] like to ask detailed questions. Is it okay if I answer your [son's/daughter's] questions? Is there anything I should not discuss?"

To caregiver:

"How do you think [patient] is going?"

"What concerns do you have at the moment?"

"What do you understand is likely to happen to [name of patient]?"

"What information will best help you to cope with your caregiving role?"

"Can you please help me to understand what I need to

know about your beliefs and practices to take the best care of you?"54

"Is there someone else you would like me to involve or speak to?"

"Every person is different. I can only tell you what usually happens to people in your situation, not exactly what will happen to you."

"I know that often people expect doctors to know what is going to happen, but in truth we can often only take educated guesses and can often be quite wrong about what the future holds, and especially how long it is. What we can be sure about is ... and what we don't know for sure is ..."

"A lot of people find it hard not knowing what will happen next or when. Is this something you find difficult?"

"I want to talk about three things today: the test results; what this will mean for you; and the treatment that is possible. And you might have some things to discuss too. Now, the test results... Do you have any questions so far?"

"Doctors sometimes forget and use words that may not be understood. Please stop me if I am doing this." 


\section{How to discuss prognosis and end-of-life issues (continued from page S90)}

- Recognise the impact of the information on the patient (and caregiver) and communicate with empathy and understanding.

- Do not make promises that cannot be delivered or that are inconsistent with clinical evidence.

- Try to foster openness and consistency of information given to the patient and the family regarding discussions of prognosis and end-of-life issues.

- To explore and address differing information needs, consider having joint as well as separate discussions with caregivers when appropriate (if the patient has given consent to discuss his or her illness).

- Explore the patient's or caregiver's emotional reaction to the information given and the meaning of the information (prognosis) to the person and respond empathically; elicit the patient's concerns.

- When spiritual or existential issues are raised, validate the importance of such topics and encourage the patient to continue to explore the issues with you, or refer where appropriate.

- Check the patient's and caregiver's understanding of what has been discussed and whether they have received the level and type of information they want or need.

- Encourage the patient or caregiver to ask questions and revisit the topic in the future when they want further information.

- At the end of the discussion:

$>$ Consider summarising the discussion

$>$ Record in the medical record what was discussed and/or write to or speak with other key health care professionals involved in the patient's care about the discussion (including the general practitioner)

$>$ Collaborate within the multidisciplinary team to ensure consistency of information (eg, unit meetings, case review).

"It sounds like this information is different from what you expected, and I think it would be upsetting for anyone." 58

"How are you feeling about what we have discussed?"

If visibly upset:

"I can see that this is really upsetting for you."

"These are important issues. Would you like to speak to a member of the hospital support staff such as a pastoral caregiver?"

"... is clearly really important to you. Would it be [useful/ helpful] to explore these issues further? Who might be the right person you can do this with?"

"Would you like to talk to someone about spiritual matters?"

"What are the things in life that give you strength and sustain you?"

"Are your beliefs being challenged by your current experiences?"

"Have I given you the information you need [at this point/so far]?"

"To make sure we are on the same wavelength, I want to check your understanding of what we have discussed."

"Is there anything I've said that you'd like me to go over?"

"We've spoken about an awful lot just now. It might be useful to summarise what we've said... Is there anything from that that you don't understand or want me to go over again?"

"Do you feel you've understood everything that you've been told? Is there anything you would like me to go over again? After all, some of this is pretty technical."

"Is there anything else you would like to discuss?"

$\mathrm{DS}^{27,35,62}$

$\mathrm{DS}^{49,53,65}$

$D^{25,53}$

$\mathrm{DS}^{31,39,47,66}$

$\mathrm{DS}^{8}$

"Is there anything from our previous discussions that you would like to revisit?"

"Don't hesitate to ask me again about any of the issues we have discussed today."

"What thoughts or questions are on your mind right now?"

"So, we've talked about... at length and also talked quickly about... Is that your recollection as well?"
$C G^{51}$

$\mathrm{DS}^{68,69}$ DS $^{28,70}$ 


\section{CLINICAL PRACTICE GUIDELINES}

and goals of treatment. ${ }^{22,77,79,80}$ Some of the reasons may be to do with patients' tendencies to forget $40 \%-50 \%$ of the information given to them by doctors; ${ }^{82}$ they may find it difficult to absorb information if they are distressed; they may not understand the language or jargon used, particularly if the information is not communicated clearly; ${ }^{83,84}$ and they may deny or subconsciously block-out information that they find unacceptable ${ }^{80,85}$ as a way of coping with their illness. ${ }^{86}$ Additionally, doctors may withhold information, particularly if there are family requests for information to be imparted through the family rather than doctor to patient, as is the case in some cultures. ${ }^{55,57}$

Many studies suggest that most patients (at least from Western countries) have high information needs concerning prognosis and life expectancy, $2,15,25,31,39,60,87-90$ however, a sizable minority do not want full disclosure. ${ }^{31}$ Many patients and caregivers want information about the likely illness trajectory, treatment options and what they may accomplish, life expectancy, likely future symptoms, and what to expect around the time of death. ${ }^{8,25,60,61,88,90-93}$ However, patients may experience conflict between wanting to know and fearing bad news. ${ }^{61}$

Although most patients have high information needs, the different types of prognostic and end-of-life information may be preferred over a series of consultations or at different times, depending on the context and the patient's stage of illness. ${ }^{26}$ Evidence suggests that patients may want less prognostic detail about their illness as they become sicker, while caregivers may want more information, especially as death approaches. ${ }^{25,52}$
Younger and more educated patients may want more detailed information. ${ }^{28,31,49,87,94}$ Some patients may never want some types of information. For example, while most patients in Western cultures want to be informed that their lifespan will be limited by their illness, some patients do not want to be given the likely timeframe. ${ }^{1,26,42,61,95}$ Patients from some cultural backgrounds may prefer non-disclosure, or disclosure negotiated through the family, when life expectancy is short. ${ }^{55,57}$

It is not possible to make assumptions about individuals' information needs based on their demographic characteristics or cultural background. It is important to tailor information to individual needs, as preferences for the amount, type and timing of information vary.

\section{General strategies to facilitate hope and coping when discussing prognosis and end-of-life issues (Box 5)}

Many health care professionals have difficulty in disclosing a limited life expectancy while maintaining the patient's hope, yet patients, caregivers and health care professionals have identified hope as an integral component of prognostic and end-of-life discussions. $^{2,25,42,60,61,63,97,98}$ These studies also emphasise the importance of balancing honesty with hope and empathy. There are different views of what constitutes an honest approach. Some studies of patients with advanced illness have found that accurate information is equated with honesty, but it was important that this was not combined with bluntness or too much hard factual or

\section{General strategies to facilitate hope and coping during prognostic and end-of-life discussions}

\section{Recommendation}

- Reassure the patient or caregiver that you (or a support system, service or team) will be there for them throughout the illness trajectory. If this is not possible, it is critical that alternative arrangements are spelt out and are reliable.

- Emphasise what can be done (particularly when disease-specific treatments are no longer working).

- Reassure the patient or caregiver that many treatments are available for controlling pain and other symptoms, where applicable.

- Some symptoms may be difficult to control, and therefore it is also important not to make unrealistic promises (such as to make the person free of pain at all times).
Useful phrases (where applicable)

Evidence level

"Our team [or whoever applicable] will do our best to support you

$\mathrm{DS}^{25,40,62}$
throughout this illness."

"I [or our team or whoever applicable] will do whatever [I/we] can to assist you in whatever lies ahead for you."

"You will not be abandoned."

If the patient is no longer able to come for outpatient follow-up:

"I will be available to discuss your care with your [GP/community nurse/ palliative care team] even if you are not able to come and see me in the clinic."

"We've been talking about some treatments that are really not going to be effective now and that we don't recommend you use. But there are a lot of other things we can still do to help and support you and make sure you are as comfortable as possible." 41

"Although this type of chemotherapy has not been useful, there are other treatments we can use to make you more comfortable."

"The aim of treatment is changing more towards maximising your function and comfort."

"I cannot give you any specific treatment to make this illness go away, but there is a lot we can offer to help you cope with it."

"We have a lot of ways to relieve [pain/nausea/dyspnoea] and other symptoms."

"We will do everything we can to ensure you are as comfortable as possible."

"We cannot promise that you will have no pain. However, we can control almost all of the pain almost all of the time." 


\section{General strategies to facilitate hope and coping during prognostic and end-of-life discussions (continued from page S92)}

Recommendation Useful phrases (where applicable)

Evidence

- Emphasise the available support, such as the palliative care team (or whatever other services are available in the local area).

- Where appropriate, explore and discuss realistic goals and expectations: facilitate realistic goals and reframe the patient's and family's expectations.

- Identify areas where control can be fostered [eg, advance care planning, enduring power of attorney (Box 11), tidying up unfinished business, arranging to see people to complete conversations].

- Where appropriate, discuss ways of coping on a day-to-day basis (eg, taking one day at a time, using strategies that allow an ongoing relationship with the family, such as writing letters or recording thoughts, focusing on important relationships).

- It is important to respect and be sensitive to the patient's ways of coping (eg, denial can be a useful coping mechanism).

- Recognise the spectrum of hope and that patients may simultaneously hope for cure as well as acknowledge the terminal nature of their illness.

- Respect the patient's wishes to explore alternative or experimental treatments aimed at controlling the underlying disease (provided adequate information has been provided to enable the patient to make an informed decision: see Box 6 and Box 7 regarding treatment decisions).

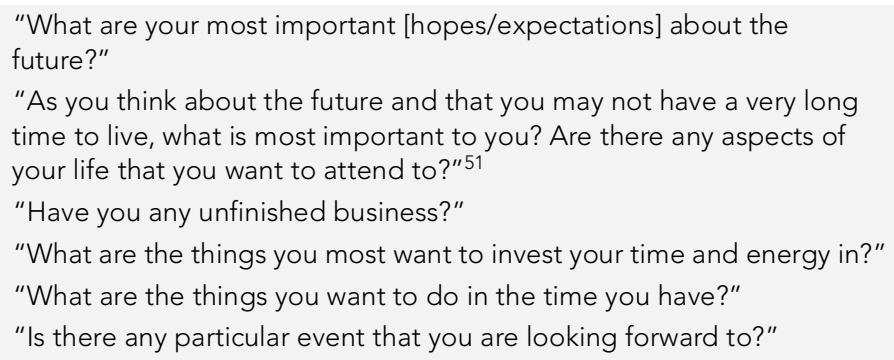

"What are your most important [hopes/expectations] about the future?"

"As you think about the future and that you may not have a very long time to live, what is most important to you? Are there any aspects of your life that you want to attend to?"51

"Have you any unfinished business?"

"What are the things you most want to invest your time and energy in?"

"What are the things you want to do in the time you have?"

"Is there any particular event that you are looking forward to?"

RGP

\begin{abstract}
"Some of my patients tell me it helps to try to take one day at a time, and live for the moment as much as possible."

"You will have good days and bad days."

"Many people find that it helps them to cope by trying to maintain some [sense of normality/normal life] or having a routine."

"Be kind to yourself and do the fun things - it doesn't have to be all about your illness."
\end{abstract}

"We can prepare for the worst while hoping for the best."

$D^{62}$

"I have no problem with you exploring alternative treatments. They are DS 25 not my area of expertise. However, if the treatments were a magic bullet, we would be aware and we would also use them. I know they are usually expensive."

"Everything has benefits and burdens. What are you hoping this therapy will achieve?"

"You must do whatever you feel is important, but remember that none of these things have been proven to work (or we would be using them) and many are very expensive." detailed information. ${ }^{42,98}$ Others have defined honesty as a straightforward or direct approach. ${ }^{2,25}$

Several studies have addressed the construct of hope within the end-of-life context. Hope can take a variety of forms, ranging from the hope of a miracle cure to the hope of a peaceful death, and patients may simultaneously hope for a cure as well as acknowledge the terminal nature of the illness. Some patients may avoid enquiring about progress or symptoms in order to maintain hope for the future. ${ }^{42,91}$ Patients have reported obtaining a sense of hope from relationships, beliefs and faith, maintaining dignity, finding inner peace, thinking about meaningful events in their lives, having symptom control and reassurance that pain will be controlled, and enjoying a sense of humour, including occasional humour from the health care professional. ${ }^{31,60}$ In addition, studies have found that hope can be maintained by having a health care professional who is knowledgeable and offers to answer all of the patient's questions, offers hope for new developments in treatment, treats the patient as a "whole person", acknowledges difficulties in giving prognostic estimates, presents information about palliative care at a rate that the patient can assimilate, and respects alternative treatments. ${ }^{25,31,99,100}$

\section{Additional background information about specific content areas and issues}

\section{Commencing or changing disease-specific treatments (eg, chemotherapy) (Box 6)}

In the setting of an advanced progressive life-limiting illness, the main goals of disease-specific treatments are to improve the length and quality of life. It is important that the patient understands that cure is not a treatment goal, but that there may be treatments that can slow the progression of the disease or provide symptom relief. Discussion should be informed and focus on the balance between the potential effectiveness of treatments on prolonging life versus the side effects. It is important that the patient has the opportunity 


\section{CLINICAL PRACTICE GUIDELINES}

\section{Commencing or changing disease-specific treatments}

\section{Recommendation}

- Be clear regarding the goals of treatments (eg, palliative rather than curative) and specifically what outcomes may be improved (eg, relief of symptoms) and how likely this can be achieved.

- State whether or not survival may be improved by the treatment.

- Where applicable, explain that shrinking the cancer will not necessarily prolong survival.

- Be proactive for quality of life and avoid recommending toxic treatments if little likely gain will result.

- Give clear information about the likely side effects, costs and time involved, to enable patients to make informed decisions in the context of their goals.

- Ensure that full supportive care will be provided whether or not any disease-specific treatment is given, and provide reassurance to this effect.

- Encourage patients to share in decision making according to their desired level of involvement.
Useful phrases (where applicable)

Evidence level

"The aim of this treatment is to help make you feel better. We DS ${ }^{28}$ will monitor the benefits and side effects of the treatment and RGP talk about the options if the treatment is not helping you."

"The aim of this treatment is not to cure, but to control the disease for as long as we can. If we control the cancer, it is likely that we will relieve some of your symptoms and make you feel better, even if we can't make you live any longer. "There is about an X\% chance that this treatment will shrink the tumour. That should make you feel better, but may only extend your life by a few [weeks/months/years]."

$\mathrm{DS}^{8,20,26,53,88,101}$

"While you receive chemotherapy for your cancer, we will still CG $^{102}$ do everything to support you as a person."

"There are a number of different [people/services] to help you along this cancer journey."

"People vary in how they want to make medical decisions. DS

Some people want to make the decisions themselves, some people want to share decision making with the doctor, and some people want the doctor to [make/give a lot of help in making] the decisions. What do you prefer?" 103

"So based on your goal of [eg, wanting to stay at home as much as possible with your family and friends], I propose that we do the following... What do you think?" 103

"Given the current situation, our options are ... I'm wondering whether... is the most suitable option for you because... What are your thoughts?" to be involved in the decision-making process, according to their desired level of involvement. ${ }^{46}$

\section{Cessation of disease-specific treatments (eg, chemotherapy) (Box 7)}

When patients hear news of lack of treatment response, clinicians should be prepared for a wide range of emotions such as sadness, anger or despair. ${ }^{109}$ It is important that such news be given in an empathic way, and the continued availability of supportive and symptomatic care is emphasised.

\section{Introducing specialist palliative care services (Box 8)}

The World Health Organization defines palliative care as:

an approach that improves the quality of life of patients and their families facing the problem associated with life-threatening illness, through the prevention and relief of suffering by means of early identification and impeccable assessment and treatment of pain and other problems, physical, psychosocial and spiritual. ${ }^{112}$

A "palliative approach" is an approach to care used by primary health care services and providers in accordance with the definition of palliative care outlined above. ${ }^{113}$ "Specialist palliative care services" refers to multidisciplinary health care services whose "substantive work is with patients who have a life limiting progressive illness". ${ }^{110}$ Specialist palliative care services are not available in all parts of Australia, especially in rural areas. In addition, not all patients with advanced progressive life-limiting illnesses require specialist palliative care services — some may be cared for most appropriately by their primary care providers. ${ }^{113}$ For patients with more complex palliative care needs (eg, those requiring specialist assessment or ongoing input for management of physical, psychological, spiritual or social issues), referral to specialist palliative care services, where available, is appropriate at any time from the first diagnosis of a progressive life-limiting illness. Patients may only need to see a specialist palliative care service initially for a limited time to assist in the management of a particular problem, such as uncontrolled pain. As the patient's illness progresses, he or she may need referral to community palliative care services or to an inpatient palliative care unit for terminal care.

In comparison to conventional care, specialist palliative care services improve patient and caregiver satisfaction, provide better pain and symptom control, reduce caregiver anxiety, and increase the likelihood of the patient being cared for during the terminal phase in their place of choice. ${ }^{114}$ However, referral to specialist palliative care services may evoke fears of impending death, helplessness and abandonment in the patient if this is not communicated sensitively and effectively by the health care team.

\section{Discussing life expectancy (Box 9)}

Various approaches to phrasing life expectancy have been reported in the context of an advanced progressive life-limiting illness: days versus weeks versus months, likelihood of being alive for certain events, rough range, and probabilistic (eg, 10\% and 50\% survival). However, whether one approach is superior to others has not been examined. Consistent findings in the literature are that it is important to avoid being exact with timeframes unless in the final 


\section{Cessation of disease-specific treatments}

\section{Recommendation}

- Sensitively explain that the disease is no longer responding to the current treatment and that continuing this treatment is likely to cause more harm than benefit.

- Avoid conveying that nothing more can be done. Emphasise that treatments and support will be provided to help them cope with their illness (see section on facilitating hope).
Useful phrases (where applicable)

Evidence level

"Your disease is no longer responding to the [eg, chemotherapy] treatment. More of this $\mathrm{CG}^{102}$ treatment would cause you more harm than good [or will give you lots of side effects but is unlikely to affect the cancer]. It is likely that you will have a better quality of life without further [type of treatment; eg, chemotherapy]."

"I wish that more chemotherapy would help this cancer, but unfortunately at this stage it will only make you sicker. Yet there are many other things we can do to help you deal with your condition." ${ }^{107}$

"The aim of treatment is now changing from trying to control the cancer to minimising the symptoms you might get."

"One of the best predictors of how someone will be able to handle chemotherapy, and how well it will work for them, is how fit and 'up and about' they are while having it. Now that you are quite weak, it is much more likely that the treatment will make you worse, not better."

"As you become sicker with this illness, we will continue to be there to provide the best $\quad$ DS $^{17,108}$ available treatments to help control the symptoms and support both you and your family."

"My aim is to optimise your comfort and ability to function as normally as possible."

"There is nothing more we can do to make this cancer go away but a lot we can do to help you [live/cope] with it." days of life, and to explain the unreliability of making survival predictions. However, research has found that patients may prefer being asked if they would like a rough idea of their life expectancy. ${ }^{15,42}$ Two studies have found that patients may prefer words or numbers to explain the prognosis instead of descriptive tools such as pie charts and graphs. ${ }^{26,35}$

\section{Discussing future symptoms and symptom management (Box 10)}

The possibility of uncontrolled pain in the future concerns many people, so it is important to offer reassurance that pain can be controlled in the vast majority. $8,25,49,61$

It is not clear whether it is appropriate for the health care professional to discuss uncommon but potentially problematic symptoms (eg, seizures and suffocation, or bleeding) and what to do should these occur. $8,20,26,53,88,101$ The benefits (of forewarning a patient or caregiver and having procedures in place) versus the potential harm (of worrying the patient or caregiver to a point of unnecessary distress about the possibility of the situation, albeit unlikely, occurring) need to be considered. Caregivers may need more specific information than the patient about how to care for the patient as the illness progresses $25,53,119$ and how to get help when complications arise at home.

\section{Advance care planning (Box 11)}

Advance care planning refers to discussion of treatment decisions and choices and goals of care at the end of life, and the patient's wishes for medical care in the future if they are no longer able to be involved in the discussion. The possible benefits of advance care planning are that it may help patients ensure that, when they are no longer able to make decisions for themselves, they receive the kind of treatment and care they would prefer. In addition, advance care planning may relieve the burden of decision making for caregivers, and facilitate open communication between patients and caregivers. ${ }^{120,125,129}$

An advance directive is a statement (either made orally or in writing) by a person that outlines their wishes for future health and personal care. The directive generally becomes effective when the person is unable to make his or her own decisions. Advance directives ${ }^{130}$ are legally binding in Australia, either at common law or under statutes. The Australian Capital Territory, Northern Territory, Queensland, South Australia and Victoria have statutory schemes for advance directives. In the other states, the law of advance directives is governed by common law. Although the evidence suggests that people are willing to write such documents, ${ }^{131}$ they may have little effect on treatment decisions, including decisions to resuscitate. ${ }^{132-134}$

In some jurisdictions, a person can make an enduring medical power of attorney, or appoint someone as an enduring guardian, whereby a family member or other trusted person is appointed to make health decisions on the person's behalf should the person lose the mental capacity to make his or her own decisions. Even in the absence of such an appointment, all Australian jurisdictions have guardianship arrangements that recognise the authority of people close to the patient to make medical treatment decisions on that person's behalf in the event of lack of decision-making capacity. Including these substitute decisionmakers in discussions has been shown to improve the effectiveness of advance care planning. ${ }^{135,136}$

In-depth discussion of advance directives and enduring medical powers of attorney are beyond the scope of these guidelines. The status of advance directives and the status and responsibilities of representatives of incompetent patients is complex and varies from jurisdiction to jurisdiction. Legal advice may need to be sought.

\section{Discussion of cardiopulmonary resuscitation (Box 12)}

It is important for health care providers to ensure that cardiopulmonary resuscitation (CPR) is not attempted inappropriately in someone who is dying an expected death, by documenting "do not attempt CPR" in the medical records. ${ }^{122,128,137,138}$ If ambulance transfers are being arranged, paramedics will also need to be informed in the manner required by the local ambulance service (check local policies and procedures).

There is considerable debate about the appropriateness of discussing CPR orders with dying patients. Some guidelines recommend that CPR should always be discussed with the patient (or family if the patient is incompetent). ${ }^{146}$ Other guidelines state that there is no 


\section{CLINICAL PRACTICE GUIDELINES}

\section{Introducing specialist palliative care services}

\section{Recommendation}

Useful phrases (where applicable)

\section{Evidence level}

- Consider referral to specialist palliative care services, where available and depending on the patient's or caregiver's needs, at any time once the treatment goal changes from curative to palliative (ie, the patient may still be receiving palliative treatments, such as chemotherapy, aimed at controlling the underlying disease).

- Refer to the palliative care health care professionals as part of the multidisciplinary team.

- Raise the topic by being honest and open and use the term "palliative care" explicitly.

- Clarify and correct misconceptions about palliative care services (particularly that it is not solely for people who are dying or associated with imminent death).

- Discuss the role of the palliative care team, emphasising expertise in symptom management as well as the wide range of support services and assistance with quality of life, and support for family, partner, children, etc.

- Explain that the patient can be linked up with the palliative care team at the same time as receiving treatments directed at the underlying disease (eg, chemotherapy).

- Explain that the patient will still be followed up by the primary health care team (eg, GP, generalist nurse) or the primary specialist (eg, oncologist, respiratory physician), where applicable.

- Discuss with the patient and caregivers what that means in terms of who they should contact for what kinds of issues or situations.
"I work closely with the palliative care team in looking after patients such as EO"11 yourself who have advanced cancer [or lung disease, etc, as appropriate to the underlying illness]."

For health care professional referring to palliative care team:

"The palliative care team can provide extra support to you and your family and help optimise your comfort and level of function."

"Extra help and support from the palliative care service might be useful now, especially if we are to give you the best and most appropriate care possible."

"The palliative care team can work closely with you and me in optimising your comfort and level of function."

"I work closely with the other doctors and nurses caring for you. The aim of palliative care is to ensure that, at all stages of your illness, you are kept as comfortable as possible, regardless of what is happening to your [cancer, heart, lungs]."

"What does the term 'palliative care' mean to you?"

"Many people have either not heard of 'palliative care', or associate it with dying in the very near future."

Then respond to the patient's cues:

"It might be useful for you if I explain what palliative care is really all about."

"Have you had any experiences with others receiving palliative care?"

"The palliative care team have a lot to offer as support. This includes pain CG ${ }^{102}$ control and the control of other symptoms resulting from the cancer."

"Palliative care includes a whole range of health care professionals who can help support you and your family at this time."

"The palliative care team works closely with me to help you live life to the full."

"[Our team/I] often work very closely and together with the palliative care CG $^{102}$ [team/services] while giving people treatment $[x] . "$

For GP or primary specialist:

"I will still be your main doctor, but the palliative care team will be able to provide extra support or advice with the best medicines for your pain."

For palliative care health care professional:

"I will work closely with [name of doctor]. Doctor... will still be your main doctor, but we will work together to ensure that you are as comfortable as
For palliative care health care professional at time of initial consultation: possible." ethical obligation either to perform or to discuss CPR when it is judged to be clinically futile. ${ }^{144,147}$ There is no common law requirement in Australia to attempt treatment, even life-prolonging treatment, which is judged to be of insufficient therapeutic benefit ("clinically futile") or is overly burdensome. 44,127,148,149 However, the use of the terms "clinical futility" and "medical futility" is also controversial, as it has been argued that such terms are not capable of objective definition and may give rise to disputes between the treatment team and the patient's family. ${ }^{150}$ There is little research evidence to guide policies about whether it is desirable to discuss "no CPR" orders with dying patients before documentation. One Australian study of patients with cancer provides support from the patient's viewpoint that CPR is not preferable when death is imminent and inevitable. ${ }^{151}$ Another study found that some patients prefer to defer the timing of the decision to the doctor and do not wish to discuss the topic. ${ }^{152}$ 


\section{Discussing life expectancy}

\section{Recommendation}

- Consider asking the patient to talk about how things have been going over the past several weeks or months and what changes they have noticed in their level of function.

- Consider explaining the factors involved with making survival predictions.

- Avoid being exact with timeframes unless in the final days of life. If giving a timeframe, explain that the lifespan will be limited by the cancer (or other illness), but that it can be very difficult to predict exactly how long a person with the condition may live.

- Give a range for timeframes.

- Emphasise the individual's unique experience.

- If a more specific timeframe is requested, offer to give this information as an estimate, but emphasise the unreliability of survival predictions.

- Various approaches may be used to phrase life expectancy, such as days versus weeks versus months, likelihood of being alive for certain events, rough range, probabilistic (eg, 10\% and $50 \%$ survival).

- Use an approach with which you are comfortable. If you are comfortable with a variety of approaches, be guided by the patient's preference; for example, ask the patient whether they would prefer to be given a rough idea (eg, weeks to months) or the chance of living a given length of time (probabilities).

- If statistics are provided, explain their limitations (eg, not specific to individual patients)
Useful phrases (where applicable)

Evidence level

"Before I answer that question I need your help to understand what changes DS ${ }^{42}$ you have noticed in your body lately. This will give an indication of how things may go. How have your energy levels been going [last week, last month]?"

"What could you do a month ago that is difficult now?"

"What has been happening to your weight and appetite?"

"Several things can affect how long a person with your condition may live, for DS ${ }^{42}$ example, how well your type of cancer [or your illness] responds to treatment, what other conditions you have etc."

"Usually we can tell time is getting short when patients are unable to get up from bed and when important organs are not working well. I think this is how things are for you now."

"It is very difficult to say how long someone has to live. I can only guess in DS 17,42 terms of days, weeks, months or years. In your case, I would 'guestimate' ..."

"Time is now limited. Death can occur at any time, although it may be several DS 17,42 days away."

"Many studies have shown that doctors are not very accurate at predicting how long a person with a serious illness like yours may live."

"It could be hours to days [or 'days to weeks', 'weeks to months' or 'months to years']."

"It might be as short as a few months or as long as several months." 115

"Most people in your situation live a few months, some live longer than that and some live shorter."

"We measure life expectancy in days, weeks, months or years. If we look at you now, it's not going to be days but more likely to be [months/years]."

"One third of people will [do well/still be alive] a year from now, half will live about 6 months. Exactly what will happen for you, I don't know."

Where probabilistic data are available and the patient requests detailed numerical or statistical information:

"Are you the kind of person who likes to know the numbers or are you more interested in the big picture?"

"It's not possible to be certain in an individual case, but based on other people l've seen in your situation, if you took a 100 people with your type of cancer and stage of illness, half of them [or 50] would still be alive in ... weeks time and 10 [or 10\%] would still be alive in ... months time. ${ }^{116}$

"The typical person with your type and stage of cancer lives ... months. This means that half the people live more than ... months and half the people live less than... months."

"On average, patients with your type and stage of cancer live... months. One quarter of patients will live... months or less and one quarter live... or more months. While I do not know for sure where you are in this group, the fact that you are feeling so poorly right now and in bed most of the time makes me concerned that you may not live longer than the average ... months." ${ }^{117}$

"We can only talk in averages here; some people do a lot better, and some a DS 27 lot worse."

"Statistics only help us understand the big patterns of illness, not exactly what will happen for an individual with that illness."
Decisions about whether to offer or provide CPR should be made on an individual basis on the grounds of likely benefit versus likely burden. Nevertheless, in situations where it is clear that the patient is dying from a far-advanced progressive life-limiting illness and the clinician has decided that CPR is not to be performed on the basis of clinical futility (ie, negligible chance of survival with or without CPR and burdens of CPR far outweigh the benefits), then it should not be presented to patients or their caregivers as if it 


\section{Discussing future symptoms and symptom management}

Recommendation

- Explore fears and misconceptions (eg, being in pain, past experience with the dying).

- Explain that most commonly the person's condition will gradually deteriorate over time, but that there may also be sudden events that no one can predict (eg, pneumonia or some other intercurrent problem).

- Describe the likely systemic symptoms as the patient's disease progresses (eg, fatigue, general weakness).

- Explain that energy levels are likely to fluctuate (eg, may have good days and bad days), but that overall there is likely to be a gradual deterioration over time.

- Discuss the implications for the patient's level of function.

- Reassure patients that pain can be controlled in most people.

- If relevant, reassure that dyspnoea may be alleviated. However, be careful not to promise that dyspnoea will be controlled at all times as it is a difficult symptom to completely contain.

- Consider whether it is appropriate to discuss potentially problematic symptoms, particularly with caregivers looking after someone at home (eg, seizures and suffocation, or bleeding, depending on the patient's illness), and what to do should these occur. The health care professional should weigh up the benefits versus the harm of such information. Reassure patients and caregivers that these symptoms are uncommon (depending on the patient's clinical circumstances), and have plans in place should these events occur. These issues may be better covered in detail closer to the time they may actually occur.

Useful phrases (where applicable)

"Is there anything that is worrying you about the future in terms of managing your symptoms?"

"People often have worries or concerns about what might happen in the future. I was wondering if you have any playing on your thoughts."

"Have you been with anyone else [going through the same thing/ dying]? How was it for them? Is there anything about what happened to them that worries you?"

"About three out of four people with cancer will deteriorate gradually DS 42 in the months before they die, so we can tell it will happen soon, but in the other one out of four people things can change very quickly (eg, heart attack, serious infection) and they may die almost unexpectedly."

"What usually happens is that you will get more and more tired and have to spend more and more time in bed."

"With time, you are likely to have less energy to do things and need more time resting. Therefore, it is important to do the things that you need or want to do now while you are still well enough. If things go well for you — well, you can just do them again."

"We are pretty good at treating pain nowadays."

"We can get on top of pain in most cases."

"You do not need to [fear/worry] that you will suffer pain."

"Shortness of breath may become more of a problem, but we have ways of controlling this."
$\mathrm{DS}^{8,25,49,61}$ RGP

$\mathrm{DS}^{8}$

DS $8,20,53,88,101$ were an appropriate treatment option. ${ }^{153}$ This does not mean that it should not be discussed (such discussions may still be an important part of terminal care), but mostly in these circumstances patients and families should not be asked to make a decision regarding CPR.

Specific discussions about CPR are recommended before documenting "no CPR" orders in the following circumstances:

- when the illness trajectory is uncertain (ie, CPR may not be clinically futile, for example a patient at an earlier stage of their illness or if a potentially reversible complication of treatment occurs);

- in response to a patient or caregiver request or question about CPR; and

- when the patient has made it clear that he or she wishes to be informed of all decisions made about their medical care.
There are other circumstances where the responsible clinician may decide that it is not appropriate to have a specific discussion about CPR with a dying patient or the family, before documenting a "no CPR' order in the medical record, including:

- the patient is aware that he or she is dying and has already expressed a wish for care that is aimed at comfort rather than prolonging life;

- the patient prefers not to discuss end-of-life care and requests that the doctor or caregiver make any decisions relating to his or her health care; and

- the patient is clearly in the terminal phase of a progressive lifelimiting illness and the doctor thinks that the harm of the discussion may outweigh the benefits. ${ }^{154,155}$

However, not discussing "no CPR" orders with patients or caregivers in this latter circumstance may be open to contest and 


\section{Advance care planning}

\section{Recommendation}

- Describe simply and clearly what advance care planning is. Give a rationale for why having these conversations can be helpful for families and the health care team.

- Explain the mechanisms available for advance care planning within the patient's state or jurisdiction.

- Involve the potential proxy decisionmaker in the discussions and planning so that he or she understands the patient's wishes.

- Develop an understanding of the patient's values and help him or her to work out goals and priorities related to his or her remaining life and treatment of the illness, and document the patient's preferences.

- Consider using clinical scenarios to structure the discussion.

- Document specific details such as timing or circumstances in which to cease blood tests, antibiotics, deactivation of implantable defibrillators, no attempt at cardiopulmonary resuscitation. Consider making reference to one of four potential levels of care, ${ }^{124}$ depending on the patient's condition at the time:

$>$ Comfort care only

> Limited care (includes comfort care): use of antibiotics and intravenous medications where appropriate, but no surgery or other more invasive measures

$>$ Surgical care: surgery and palliative chemotherapy where appropriate, but no ventilation or resuscitation except during and after surgery

$>$ Intensive care: includes all possible treatments, including invasive measures, to maintain life (it may not be appropriate to offer this level of care for this patient population).

- Emphasise that advance care planning is an ongoing process that will need to be reviewed and updated periodically, as the patient's wishes may change over time, particularly with major health changes.
Useful phrases (where applicable)

\section{Evidence level}

"Have you thought about the type of medical care you would like to have if you ever became too sick to speak for yourself? That is the purpose of advance care planning, to ensure that you are cared for the way you would want to be, even when communication may be impossible." ${ }^{120}$

"Do you know who would make decisions about your medical treatment if you were unable to make them for yourself? Is this the right person?"

"Have you spoken to the person who will make decisions for you? Would you like to include them in these discussions, so they know what is happening and what might happen in future?"

"Some people have thought about what they want and document their wishes in what is called an advance care directive. Do you have an advance care directive? Would you like to complete one? I could get you some more information if you like, or refer you to someone who could explore this further with you."

"It's often easier to talk through tough decisions when there isn't a crisis." 121

"Have you talked to anyone about your wishes, if you become too unwell to make decisions for yourself, about potentially lifeprolonging treatment? Have you talked to your family or general medical practitioner about what you want?"

"Sometimes people with your type of illness lose the ability to DS ${ }^{123}$ make decisions [or communicate their wishes] as the illness progresses. Who would make decisions for you if you were unable to do this for yourself?"

If the person can identify a substitute decisionmaker:

"Would you like to talk this through with them?"

"Would you like me to assist you with this?"

"Each person has personal goals and values that influence their DS ${ }^{125}$ decision when discussing advance care planning. I would like to $\mathrm{CG}^{120,122}$ find out your goals regarding your health and your health care and the things you most value in life. For some people, the goal $\mathrm{EO}^{122-124,126}$ may be to prolong life; for others, relief of suffering, optimising quality of life; and for others, a comfortable and peaceful death. I suggest we go through examples of possible situations that may arise to help you decide your goals of care."

"These are discussions we may need to revisit if there are $\mathrm{CG}^{120,122,127}$ changes in the course of your illness." 


\section{CLINICAL PRACTICE GUIDELINES}

\section{Advance care planning (continued from page S99)}

\section{Recommendation}

Useful phrases (where applicable)

- Ensure that other health care professionals who are $\mathrm{CG}^{128}$ involved with the patient's care are aware of the patient's wishes. If an advance directive is completed, make sure its existence is known by all treating health care professionals and it is available when the patient's place of care is being changed (eg, from home or nursing home to hospital, during ambulance transfers).

\section{2 "No CPR" orders}

\section{Recommendation}

- "No CPR" orders should not be discussed in isolation, but rather in the context of a general discussion about prognosis, the patient's values and expectations, and the goals of care.

- Check the patient's or caregiver's understanding of cardiopulmonary resuscitation (CPR).

- Give a simple explanation of CPR, making it clear that it was designed for previously well people with acute cardiopulmonary events. It is not necessary to give a detailed description of CPR unless the patient or caregiver requests clarification.

- Explain that when a person has a cardiac or respiratory arrest in an acute care facility or during ambulance transfers (eg, between care settings), it is standard procedure for CPR to be attempted unless it is documented otherwise (ie, "no CPR" order is in place).

- Avoid describing CPR as "doing everything", as this can be easily misinterpreted (eg, the implication of not doing CPR is that it means "doing nothing").

- When the clinician judges CPR to have no therapeutic benefit, explain that in your judgement CPR would have no chance of changing the course of their illness.

- Consider reinforcing this by explaining that most people think CPR in hospitalised patients is successful. However, the success rate of CPR in previously healthy people is low. The outcome of CPR in people with a serious illness is universally poor.
Useful phrases (where applicable)

\section{Evidence leve}

$\mathrm{CG}^{120}$

$\mathrm{CG}^{128}$

"Are you familiar with CPR?"

"What is your understanding of CPR?"

"Do you know what CPR means?"

"Cardiopulmonary resuscitation or CPR is given when a person's RGP heart stops beating or breathing stops. It is used to keep people alive temporarily until they can receive emergency treatment in hospital or until an ambulance arrives."

If more detail required:

"The chest is pumped and air is blown into the lungs to try to get the person's heart and breathing started again. In a hospital setting (or if an ambulance is called), it will also involve needles in a vein, tubes down the throat and potentially an electric shock to the chest."

"If an ambulance is called, the ambulance officers cannot diagnose; their primary role is to keep someone alive long enough to get to an emergency department. ${ }^{137}$ It is standard policy for ambulance officers to start CPR in response to a cardiac arrest unless it is documented otherwise."

"We will continue to do everything that is possible to ensure your comfort."

"I think we need to focus on making sure you are as comfortable $\mathrm{CG}^{128}$ and as active as possible. There are no invasive measures that are going to change the course of the illness now and we need to focus clearly on your comfort."

"Our aim is to focus on your comfort. No measures are going to change the course of your cancer."

"Given the severity of your illness, CPR has almost no chance of CG ${ }^{45}$ being effective. ${ }^{140}$ It might also mean that you cannot be with your family when you are close to death. I would recommend that we do not attempt it in your case, but I can reassure you that we will continue all treatments that are potentially effective for your comfort. What do you think about that?"

"Allowing death to come naturally and making sure that you are as comfortable and supported as possible is our goal when that time comes. Trying to reverse that process and prolong life with CPR at that time is almost certainly going to fail and we would not recommend we try and do so. Is that in keeping with your thoughts and wishes?" 


\section{2 "No CPR" orders (continued from page S100)}

\section{Recommendation}

- Where appropriate, explain that the patient's death is inevitable and that the aim is to ensure that death is as comfortable as possible.

- If CPR is judged to be clinically futile, do not ask the patient or caregiver "What do you want done?" when the patient dies, as this creates an inappropriate burden of choice when there is no choice to be made.

- Emphasise active support throughout the dying process and explain that all potentially effective treatments can still be given even if they have a "no CPR" order.

- The "no CPR" order should be clearly documented and state whether it has been discussed with the patient and/or their caregiver (and if discussed with caregivers, include their names). Document that the focus should be on providing good palliative care, and specifically that "CPR should not be attempted".

- Where a decision has been made not to involve the patient or their surrogate in decisions regarding "no CPR" orders, an explanation should be recorded regarding the rationale for this.

- "No CPR" orders should include a statement of the patient's underlying condition or prognosis justifying it, and the involvement of other health care professionals in the decision-making process or discussion where applicable.

- Check with your hospital or facility policy about any other requirements for documenting "no CPR" orders.
Useful phrases (where applicable)

Evidence level

"Not giving CPR does not mean that we are giving up on you. $\mathrm{DS}^{40,123}$

On the contrary, we will continue to be extremely active and

supportive in our care for you. It simply means that when death does eventually come, our focus will be on keeping you comfortable and supported rather than prolonging the dying period."

"Allowing death to come unhindered and naturally, and making EO144 sure that you are as comfortable and supported as possible is our goal when that time comes. From what we have already spoken about this would seem in keeping with your wishes. Is this so?"

"Putting in place a 'no CPR' order does not mean that we will CG $^{127}$ abandon doing everything we can for [patient's] comfort and functioning. While some of the treatments have made small differences, it seems clear at this point that [patient] will probably not recover. Certainly more [chemotherapy/aggressive treatment] can't make [him/her] better at this point. We need to help [him/her] in ways that we know can make a difference for the better. We need to ensure that [he/she] doesn't suffer unnecessarily and that [he/she] is allowed to die in peace and comfort. Here's what I am proposing to do; we'll watch [him/her] carefully and make sure we do everything necessary to make [him/her] comfortable. When [he/she] dies, we'll respond with humanity and kindness and not with futile measures involving machines and drugs. How do you feel about this?"145

"CPR would not be helpful. It would not prevent the patient's death but may prolong their dying and cause more suffering." requires very careful consideration. Specific recommendations about whether to discuss CPR before documenting "no CPR" orders in such circumstances are beyond the scope of these guidelines. Health care professionals should refer to relevant professional and institutional codes of ethics and policies, and to relevant judgments and statutory law, for advice on this matter.

Box 12 gives recommendations for communication about CPR should the clinician decide that such a discussion is appropriate. If discussing CPR, it is important to check that patients are aware of the poor success rate of CPR in patients with their condition. When patients and families are made aware of the facts, they are less likely to request CPR. ${ }^{156}$

When it is judged inappropriate to discuss "no CPR" orders with a particular patient or the family, the reason it has not been specifically discussed should be documented in the patient's medical records. ${ }^{153}$

\section{Discussing the process of death and dying (Box 13)}

Once the patient is approaching the terminal phase of the illness, or earlier depending on the patient's or caregiver's information need, it is important to explore specific issues related to the process of death and dying, as many patients and caregivers hold misconceptions about what is likely to happen, and may hold unnecessary fears. ${ }^{1,8}$ Some studies show that patients and caregivers may have differing information needs as the patient's illness progresses. ${ }^{8,25,53}$ Caregivers may prefer more detailed information about the dying process, potential complications and immediate post-death arrangements than patients. ${ }^{8,25,53}$ 


\section{CLINICAL PRACTICE GUIDELINES}

\section{Discussing the process of death and dying}

Recommendation

- Explore fears and dispel myths.

- Explore the patient's preferred place of death or dying.

- Recognise that the situation may change (eg, person may not wish to die at home, but to be at home as long as possible).

- Consider explaining the likelihood of decreasing consciousness levels as death approaches.

- Explain that they will gradually become weaker, needing longer rest periods and eventually become less conscious.

- Promote understanding of the decreased need for fluid and foods, non-essential medications, routine observations, tests and investigations in the final days.

- Consider reassuring patients and caregivers that dying will neither be inappropriately prolonged nor hastened by any treatments or medications given in the patient's final days.

- Consider warning families that dying may be a slow process.
Useful phrases (where applicable)

Evidence level

"It is very difficult for any of us to contemplate our own death. Are there particular DS ${ }^{1,8}$ fears or issues concerning you about dying?"157

"People who have an illness such as yours sometimes experience worries or concerns about how they will manage as their disease progresses. Is this something on your mind?"

"Have you had any thoughts about where you would like to be when you get sicker RGP with this illness - where you would like to be cared for when you die?"

"When talking about dying, some people are very clear where they would want this to happen. Some want to die at home, others in a hospice and others in hospital. Do you have any particular wishes?"

"In your final days, you may gradually go into a coma, which is like a deep sleep. However, it is not the same as sleep and going to sleep at night won't make this happen any sooner."

"Often what happens is that people become more and more drowsy, and less and less aware of what is going on around them. As far as we can tell, this is not distressing or frightening at all. If you do become distressed, however, we will do our best to ease this as quickly as possible. We will also be there for your family at this time to help support them if necessary."

"We will not be measuring your blood pressure and pulse on a regular basis any more, but will be concentrating on relieving your symptoms."

"Some of these tablets will not be of any help at this stage and may be difficult to swallow."

"Intravenous fluids are unlikely to alter the course of the disease and at this time they may pool in the lungs and make breathing more difficult."

"We have discontinued most of [his/her] medications as [he/she] can't take them by mouth anymore and they will not make any difference at this stage. We will continue all the medications that are essential, but give them in a form [he/she] can manage."

\section{Regarding an unconscious patient:}

"It is likely that [patient's name] will die within the next couple of days. However, sometimes it takes longer, even up to a week or so. So it is important for you to look after yourself at this time, maybe take shifts with other family members. Otherwise you may get completely exhausted if you are unable to leave [his/her] side for that amount of time."

\section{Difficult scenarios such as requests by family members to withhold information, family conflicts and unrealistic requests by patients (Boxes 14 to 16 )}

The information preferences and autonomy of the patient are paramount, yet it is vital to include family members in discussions surrounding the transition from curative to palliative care. ${ }^{163}$ The difficulty of negotiating the concerns of family members while also respecting the patient's wellbeing and autonomy adds complexity to the task of discussing prognosis and end-of-life issues in a palliative care setting. There is also the potential complicating factor of requests by family members (often a culturally related issue, as discussed above) to withhold information from the patient. Various approaches have been reported in studies of mainly health care professionals' views and in the empirical literature regarding these issues. No studies have been conducted to evaluate benefits of one approach over another. As for all issues, it is important to make repeated efforts to help family members understand the patient's condition. ${ }^{145}$ These guidelines present various ways of addressing these issues based on research, expert opinion and other guidelines. A combination of approaches, or different approaches depending on the circumstances, may be appropriate.

It is important to address conflict rather than avoid it, so that patients and families have the opportunity to share in decision making and be satisfied with care. As for all sections in these guidelines, the use of empathy is important in helping patients and family members feel respected and understood. Research shows that patients who feel understood and listened to are more prepared to accept their doctor's recommendation. ${ }^{164}$

In the context of palliative care, denial may be defined as "an unconscious mechanism aimed at negating a disease-oriented threat to the integrity of personhood and daily life". ${ }^{165}$ It may involve avoidance of reality. The use of denial by patients is not always counterproductive to their wellbeing. It can reduce psychological distress and help them absorb the consequences of lifethreatening information in a manageable and self-determined timeframe. ${ }^{165}$ It is not problematic if it does not affect the patient's ability and desire to seek and accept help. ${ }^{165}$ However, patients or family members may request medically futile treatments because of refusal to accept the diagnosis or prognosis of a life-limiting 


\section{Requests by family members to withhold prognostic or end-of-life information from the patient}

- Show respect for the family and the fact that they

may have different views from your own about

truth telling and patient autonomy.

- Clarify the reasons why the family wants to withhold information from the patient and explore their concerns with telling the patient.

- Explain that patients are often aware that they have a terminal prognosis even if it has not been openly acknowledged, and that it can be very frightening and isolating for the patient to not be able to talk about it.

- In a sensitive way, negotiate with the family to explore the patient's understanding of his or her illness, concerns and fears, desire for information, and wishes to be involved in decisions about his or her medical care (and if he or she does not wish to be involved or informed, who he or she would like to make decisions).

- Use an official interpreter if one is needed.

- Consider speaking with the patient both with and without the family present.

- Explain that you will not give more information than desired by the patient. However, you are ethically obliged to give the patient the opportunity to ask questions about the illness and to respond honestly.
"Why do you not want me to tell?"

"What are you afraid I will say?"158

"I understand that you are worried about me talking to [patient's name] about what is going on at the moment. We certainly wouldn't want to tell [patient's name] about the situation either if [he/she] doesn't want to know. What is it that you think will happen to [patient's name] if we do have this conversation? What do you think will happen if we don't tell [patient's name] about what is happening at the moment?"

"What are you frightened may happen?"

"Has [patient's name] specifically asked you to have me withhold information?"

"In my experience, people are often more stressed and frightened by DS ${ }^{53}$ the unknown than by the truth told gently."

"Do you think [patient's name] knows that all is not right at the moment? What must that be like for [patient's name] to suspect but not know?"

"It is likely that [patient's name] understands completely what is going on. Sometimes it is a huge relief to all concerned if it is brought into the open."

"By not acknowledging what is happening, we are blocking [patient's name]'s ability to have some really important conversations."

"I would like to ask [patient's name] what [he/she] thinks is happening EO $\mathrm{O}^{73,158}$ to [him/her]. [He/she] may know more than you realise."

"We could talk to [patient's name] together and find out what [he/she] thinks is happening and what else [he/she] would like to know."

"I will always answer truthfully if [he/she] asks a direct question. But I DS ${ }^{53}$ will not force or push any information on [patient's name] that [he/she] does not want." illness. Such treatments may have side effects that interfere with quality of life and the completion of unfinished business when time is limited. In this case, denial is a problem that the health care professional should address.

Patient requests for medically futile treatments may represent denial or a lack of prognostic understanding. It is important to determine the reason for the request before giving new information.

\section{Role of self-care}

At the end of the discussion, it is important to reflect on how the discussion went and how it could be improved next time, as well as recognising the emotional impact of the discussion on oneself and the need for self-care. Discussing prognosis and end-of-life issues in patients with advanced life-limiting illnesses is not easy. Eliciting patients' and caregivers' emotional concerns and responding empathically involves giving of oneself emotionally, and can take its toll. Not only do health care professionals have to deal with the patient's emotions and concerns, but potentially their own feelings of failure, helplessness and frustration arising from advancing illness, which may be compounded by stresses in their private lives. ${ }^{166,167}$ If health care professionals are to be encouraged to discuss prognosis and end-of-life issues with people who have advanced life-limiting illnesses, it is important to acknowledge the need for support and self-care of the health care professionals. Such support includes debriefing with colleagues, encouraging the development of strong collaborative team relationships, and providing communication skills training. ${ }^{74}$ 


\section{CLINICAL PRACTICE GUIDELINES}

15 Dealing with conflicts (eg, differing family opinions, conflicts between doctor and patient or doctor, patient and caregiver)

Recommendation
- Identify and recognise family discord as early as possible and make other members of the health
care team aware if it is likely to affect the patient's care.

- Offer meetings (on repeated occasions if needed) with the patient and/or key family members or caregivers to explore concerns and to try to increase understanding about the patient's condition.

- Allow the patient and family time to come to terms with the impending death of the patient.

- Continually focus on what is known about the patient's values and preferences.

- Explore and acknowledge the emotional issues and concerns of the patient or caregiver that are not always expressed and that may result in frustrating communication barriers.

- If possible, negotiate a family spokesperson, preferably one nominated by the patient if feasible,

Useful phrases

(where applicable)

Evidence

level

RGP

$\mathrm{EO}^{145}$

$\mathrm{CG}^{127}$

"If [he/she] were able to talk to us, what do you think [he/ she] would want us to know?"

$\mathrm{EO}^{145}$ who can be involved in medical decisions when the patient is too sick to be involved and who can communicate with the rest of the family.

- Preferably have someone with you (another health care professional or patient liaison officer) and document all discussions clearly in the notes.

- Openly negotiate with patients and family members to try to reach a mutually acceptable solution.

- Recognise limitations (ie, you are unlikely to resolve longstanding family dysfunction).

- When these efforts are not successful and the conflict is affecting the patient's care, consider arranging a second opinion for the family, or a skilled communicator to facilitate a patient care conference, or a patient advocate if there are unresolved issues between health care professionals and the family or patient.
$\mathrm{DS}^{53}$

$\mathrm{CG}^{159}$

RGP

$\mathrm{DS}^{35}$

RGP

$\mathrm{EO}^{160}$

\section{Dealing with denial or expectations that are not consistent with clinical evidence (eg, requests for medically futile treatments)}

\section{Recommendation}

- Explore patient understanding.

- Use a hypothetical question to explore goals and important things that need to be done while well enough.

- Check for a "window" in which to address the situation realistically (eg, check if there were times when the patient did not feel so optimistic).

- Do not force confrontation about denial, otherwise it may lead to psychological distress, further denial or alienation from the health care professionals. Allow patients to fantasise about unlikely possibilities if they otherwise seem fairly realistic and prepared, especially if it is not blocking them from doing important end-of-life work (administrative, conversations with family).

- Referral for second opinion may be offered if the patient or caregiver will not accept that the treatment is medically futile.
Useful phrases (where applicable)

"What is your understanding of what is likely to happen with your DS illness and future treatment options?"

"While we are hoping that things will go well with treatment... or be DS 62 possible for... to occur, if by some chance you didn't get better, what would be the most important things that you would want or need to do while you are still able to?"

"I wish too that this disease would get better. If we cannot make that happen, what other shorter-term things would you like to achieve?"

"Have you thought about what might happen if things don't go as you wish? Sometimes having a plan that prepares you for the worst makes it easier to focus on what you hope for most." 41

"I know you are hoping that the treatment will work well, but I feel it is important to talk about 'what if'."

"I can see that you really want to get better and I would like that too. EO I61 $^{161}$ Are there ever times when you have darker moments and don't feel that things are going so well? Can you tell me what is on your mind during those times?"

"That would be wonderful if... were to occur, wouldn't it? Are there EO $\mathrm{O}^{161}$ times when it doesn't seem so sure? Would you like to talk about that?"

"Sometimes it helps to talk these difficult things through with another DS"9,162 experienced doctor. Would you like me or your GP to ask for a second opinion?"

These recommendations can also be applied to those in Box 6 . 


\section{COMMUNICATING PROGNOSIS AND END-OF-LIFE ISSUES}

\section{References}

1 Steinhauser KE, Christakis NA, Clipp EC, et al. Factors considered important at the end of life by patients, family, physicians, and other care providers. JAMA 2000; 284: 2476-2482.

2 Wenrich MD, Curtis JR, Shannon SE, et al. Communicating with dying patients within the spectrum of medical care from terminal diagnosis to death. Arch Intern Med 2001; 161: 868-874.

3 Parker S, Clayton JM, Hancock K, et al. Communication of prognosis and issues surrounding end of life (EOL) in adults in the advanced stages of a life-limiting illness: a systematic review. Sydney: University of Sydney, NHMRC Clinical Trials Centre, 2006. http://www.ctc.usyd.edu.au/ research/publications/articles_2006.htm (accessed Apr 2007).

4 Higgins JPT, Green S, editors. Cochrane handbook for systematic reviews of interventions 4.2.5 [updated May 2005]. In: The Cochrane Library, Issue 3, 2005. Chichester, UK: John Wiley \& Sons, Ltd.

5 National Health and Medical Research Council. Guidelines for the development and implementation of clinical practice guidelines. Canberra: AGPS, 1995.

6 National Health and Medical Research Council. A guide to the development, implementation and evaluation of clinical practice guidelines. Canberra: NHMRC, 1999. http://www.nhmrc.gov.au/publications/synopses/cp30syn.htm (accessed May 2007).

7 Raine R, Sanderson C, Black N. Developing clinical guidelines: a challenge to current methods. BMJ 2005; 331: 631-633.

8 Clayton JM, Butow PN, Arnold RM, Tattersall MHN. Discussing end-oflife issues with terminally ill cancer patients and their carers: a qualitative study. Support Care Cancer 2005; 13: 589-599.

9 Fellowes D, Wilkinson S, Moore P. Communication skills training for health care professionals working with cancer patients, their families and/ or carers. Cochrane Database Syst Rev 2003; (2): CD003751.

10 Gysels M, Richardson A, Higginson I. Communication training for health professionals who care for patients with cancer: a systematic review of effectiveness. Support Care Cancer 2004; 12: 692-700.

11 VandeKieft GK. Breaking bad news. Am Fam Physician 2001; 64: 19751978.

12 Mueller PS. Breaking bad news to patients: the SPIKES approach can make this difficult talk easier. Postgrad Med 2002; 112: 15-16, 18.

13 Baile W, Lenzi R, Parker A, et al. Oncologists' attitudes toward and practices in giving bad news: an exploratory study. J Clin Oncol 2002; 20: 2189-2196

14 Christakis NA, Iwashyna TJ. Attitude and self-reported practice regarding prognostication in a national sample of internists. Arch Intern Med 1998; 158: 2389-2395.

15 Clayton JM, Butow PN, Tattersall MHN. When and how to initiate discussion about prognosis and end-of-life issues. J Pain Symptom Manage 2005; 30: 132-144.

16 Chochinov HM, Wilson KG, Enns $M$, et al. Desire for death in the terminally ill. Am J Psychiatry 1995; 152: 1185-1191.

17 Morita T, Akechi T, Ikenaga M, et al. Communication about the ending of anticancer treatment and transition to palliative care. Ann Oncol 2004; 15: 1551-1557.

18 Chochinov HM, Tataryn DJ, Wilson KG, et al. Prognostic awareness and the terminally ill. Psychosomatics 2000; 41: 500-504

19 Schofield PE, Butow PN, Thompson JF, et al. Psychological responses of patients receiving a diagnosis of cancer. Ann Oncol 2003; 14: 48-56.

20 Fallowfield LJ, Jenkins VA, Beveridge HA. Truth may hurt but deceit hurts more: communication in palliative care. Palliat Med 2002; 16: 297-303.

21 Tattersall MH, Gattellari M, Voigt K, Butow PN. When the treatment goal is not cure: are patients informed adequately? Support Care Cancer 2002; 10: 314-321.

22 Weeks JC, Cook EF, O'Day SJ, et al. Relationship between cancer patients' predictions of prognosis and their treatment preferences. JAMA 1998; 279: 1709-1714.

23 The AM, Hak T, Koeter G, van der Wal G. Collusion in doctor-patient communication about imminent death: an ethnographic study. West $J$ Med 2001; 174: 247-253.

24 Emanuel EJ, Fairclough DL, Wolfe P, Emanuel LL. Talking with terminally ill patients and their caregivers about death, dying, and bereavement: is it stressful? Is it helpful? Arch Intern Med 2004; 164: 1999-2004.

25 Kirk P, Kirk I, Kristjanson LJ. What do patients receiving palliative care for cancer and their families want to be told? A Canadian and Australian qualitative study. BMJ 2004; 328: 1343-1347.
26 Hagerty RG, Butow PN, Ellis PA, et al. Cancer patient preferences for communication of prognosis in the metastatic setting. J Clin Oncol 2004; 22: 1721-1730

27 Gordon EJ, Daugherty CK. 'Hitting you over the head': oncologists' disclosure of prognosis to advanced cancer patients. Bioethics 2003; 17: 142-168.

28 Norton SA, Talerico KA. Facilitating end-of-life decision-making: strategies for communicating and assessing. J Gerontol Nurs 2000; 26(9): 6-13.

29 Norton SA, Bowers BJ. Working toward consensus: providers' strategies to shift patients from curative to palliative treatment choices. Res Nurs Health 2001; 24: 258-269.

30 Yun YH, Lee CG, Kim SY, et al. The attitudes of cancer patients and their families toward the disclosure of terminal illness. J Clin Oncol 2004; 22: 307-314.

31 Hagerty RG, Butow PN, Ellis PM, et al. Communicating with realism and hope: incurable cancer patients' views on the disclosure of prognosis. $J$ Clin Oncol 2005; 23: 1278-1288.

32 Teno JM, Clarridge BR, Casey V, et al. Family perspectives on end-of-life care at the last place of care. JAMA 2004; 291: 88-93.

33 Butow PN, Kazemi JN, Beeney LJ, et al. When the diagnosis is cancer: patient communication experiences and preferences. Cancer 1996; 77: 2630-2637.

34 Schofield PE, Beeney LJ, Thompson JF, et al. Hearing the bad news of a cancer diagnosis: the Australian melanoma patient's perspective. Ann Oncol 2001; 12: 365-371.

35 Butow PN, Dowsett S, Hagerty R, Tattersall MH. Communicating prognosis to patients with metastatic disease: what do they really want to know? Support Care Cancer 2002; 10: 161-168.

36 Curtis JR, Engelberg RA, Nielsen EL, et al. Patient-physician communication about end-of-life care for patients with severe COPD. Eur Respir $J$ 2004; 24: 200-205

37 Girgis A, Sanson-Fisher RW, Schofield MJ. Is there consensus between breast cancer patients and providers on guidelines for breaking bad news? Behav Med 1999; 25: 69-77.

38 Friedrichsen $M$. Breaking bad news in the transition from curative to palliative cancer care - patient's view of the doctor giving the information. Support Care Cancer 2000; 8: 472-478.

39 Curtis JR, Wenrich MD, Carline JD, et al. Understanding physicians' skills at providing end-of-life care perspectives of patients, families, and health care workers. J Gen Intern Med 2001; 16: 41-49.

40 Pentz RD, Lenzi R, Holmes F, et al. Discussion of the do-not-resuscitate order: a pilot study of perceptions of patients with refractory cancer. Support Care Cancer 2002; 10: 573-578.

41 Tulsky JA. Beyond advance directives: importance of communication skills at the end of life. JAMA 2005; 294: 359-365.

42 Clayton J, Butow P, Arnold R, Tattersall M. Discussing life expectancy with terminally ill cancer patients and their carers: a qualitative study. Support Care Cancer 2005; 13: 733-742.

43 Makoul G. Essential elements of communication in medical encounters: the Kalamazoo consensus statement. Acad Med 2001; 76: 390-393.

44 Girgis A, Sanson-Fisher RW. Breaking bad news: consensus guidelines for medical practitioners. J Clin Oncol 1995; 13: 2449-2456.

45 Palliative Care Expert Group. Therapeutic guidelines: palliative care. Melbourne: Therapeutic Guidelines Limited, 2005.

46 National Breast Cancer Centre Advanced Breast Cancer Working Group. Clinical practice guidelines for the management of advanced breast cancer. Canberra: NHMRC, 2001. http://www.nhmrc.gov.au/publications/ synopses/cp76syn.htm (accessed May 2007).

47 Sapir R, Catane R, Kaufman B, et al. Cancer patient expectations of and communication with oncologists and oncology nurses: the experience of an integrated oncology and palliative care service. Support Care Cancer 2000; 8: 458-463.

48 Steinhauser KE, Clipp EC, McNeilly M, et al. In search of a good death: observations of patients, families, and providers. Ann Intern Med 2000; 132: 825-832.

49 Rose KE. A qualitative analysis of the information needs of informal carers of terminally ill cancer patients. J Clin Nurs 1999; 8: 81-88.

50 Emanuel LL, von Gunten CF, Ferris FD, editors. Communicating bad news. In: The Education for Physicians on End-of-life Care (EPEC) curriculum. Chicago: The Robert Wood Johnson Foundation, 1999.

51 Schofield P, Carey M, Love A, et al. 'Would you like to talk about your future treatment options?' Discussing the transition from curative cancer treatment to palliative care. Palliat Med 2006; 20: 397-406. 


\section{CLINICAL PRACTICE GUIDELINES}

52 Butow PN, Maclean M, Dunn SM, et al. The dynamics of change: cancer patients' preferences for information, involvement and support. Ann Oncol 1997; 8: 857-863.

53 Clayton JM, Butow PN, Tattersall MHN. The needs of terminally ill cancer patients versus those of caregivers for information regarding prognosis and end-of-life issues. Cancer 2005; 103: 1957-1964.

54 Rabow MW, Hauser JM, Adams J. Supporting family caregivers at the end of life: "they don't know what they don't know". JAMA 2004; 291: 483-491.

55 Goldstein D, Thewes B, Butow P. Communicating in a multicultural society. II: Greek community attitudes towards cancer in Australia. Intern Med J 2002; 32: 289-296.

56 Orana C, Koenig B, Davis AJ. Cultural aspects of nondisclosure. Camb Q Healthc Ethics. 1994; 3: 338-346.

57 Huang X, Butow P, Meiser B, Goldstein D. Attitudes and information needs of Chinese migrant cancer patients and their relatives. Aust NZ J Med 1999; 29: 207-213.

58 Back AL, Arnold RM. Dealing with conflict in caring for the seriously ill: "it was just out of the question". JAMA 2005; 293: 1374-1381.

59 Yardley SJ, Davis CL, Sheldon F. Receiving a diagnosis of lung cancer: patients' interpretations, perceptions and perspectives. Palliat Med 2001; 15: 379-386.

60 Greisinger AJ, Lorimor RJ, Aday LA, et al. Terminally ill cancer patients: their most important concerns. Cancer Pract 1997; 5: 147-154.

61 Kutner JS, Steiner JF, Corbett KK, et al. Information needs in terminal illness. Soc Sci Med 1999; 48: 1341-1352.

62 Clayton JM, Butow PN, Arnold RM, Tattersall MHN. Fostering coping and nurturing hope when discussing the future with terminally ill cancer patients and their caregivers. Cancer 2005; 103: 1965-1975.

63 Grbich C, Parker D, Maddocks I. Communication and information needs of care-givers of adult family members at diagnosis and during treatment of terminal cancer. Prog Palliat Care 2000; 8: 345-350.

64 Carter H, MacLeod R, Brander P, McPherson K. Living with a terminal illness: patients' priorities. J Adv Nurs 2004; 45: 611-620.

65 Friedrichsen MJ. Justification for information and knowledge: perceptions of family members in palliative home care in Sweden. Palliat Support Care 2003; 1: 239-245.

66 Heaven CM, Maguire P. Disclosure of concerns by hospice patients and their identification by nurses. Palliat Med 1997; 11: 283-290.

67 Lobb EA, Kenny DT, Butow PN, Tattersall MH. Women's preferences for discussion of prognosis in early breast cancer. Health Expect 2001; 4: 4857.

68 Barnett MM. Effect of breaking bad news on patients' perceptions of doctors. J R Soc Med 2002; 95: 343-347.

69 Bradley EH, Hallemeier AG, Fried TR, et al. Documentation of discussions about prognosis with terminally ill patients. Am J Med 2001; 111: 218-223.

70 Brown RF, Butow PN, Henman M, et al. Responding to the active and passive patient: flexibility is the key. Health Expect 2002; 5: 236-245.

71 Cox A, Holbrook D, Rutter M. Psychiatric interviewing techniques VI. Experimental study: eliciting feelings. Br J Psychiatry 1981; 139: 144-152.

72 Lo B, Quill T, Tulsky J. Discussing palliative care with patients. ACP-ASIM End-of-Life Care Consensus Panel. American College of PhysiciansAmerican Society of Internal Medicine. Ann Intern Med 1999; 130: 744749.

73 Maguire P, Piceathly C. Learning counselling. In: Doyle D, Hanks G, Cherny N, Calman K, editors. Oxford textbook of palliative medicine. New York: Oxford University Press, 2004.

74 Schofield P, Ball D, Smith JG, et al. Optimism and survival in lung carcinoma patients. Cancer 2004; 100: 1276-1282.

75 Degner LF, Kristjanson LJ, Bowman D, et al. Information needs and decisional preferences in women with breast cancer. JAMA 1997; 277: 1485-1492.

76 Haidet P, Hamel MB, Davis RB, et al. Outcomes, preferences for resuscitation, and physician-patient communication among patients with metastatic colorectal cancer. SUPPORT Investigators. Study to Understand Prognoses and Preferences for Outcomes and Risks of Treatments. Am J Med 1998; 105: 222-229.

77 Teno J, Lynn J, Wenger N, et al. Advance directives for seriously ill hospitalized patients: effectiveness with the patient self-determination act and the SUPPORT intervention. SUPPORT Investigators. Study to Understand Prognoses and Preferences for Outcomes and Risks of Treatment. J Am Geriatr Soc 1997; 45: 500-507.
78 Chan A, Woodruff RK. Communicating with patients with advanced cancer. J Palliat Care 1997; 13: 29-33.

79 Mackillop WJ, Stewart WE, Ginsburg AD, Stewart SS. Cancer patients' perceptions of their disease and its treatment. $\mathrm{Br} J$ Cancer 1988; 58: 355-358.

80 Gattellari M, Butow PN, Tattersall MH, et al. Misunderstanding in cancer patients: why shoot the messenger? Ann Oncol 1999; 10: 39-46.

81 Fried TR, Bradley EH, O'Leary J. Prognosis communication in serious illness: perceptions of older patients, caregivers, and clinicians. J Am Geriatr Soc 2003; 51: 1398-1403.

82 Ley P. Towards better doctor-patient communications. In: Bennett AE, editor. Communications between doctors and patients. Oxford: Oxford University Press, 1976: 77-96.

83 Lobb EA, Butow PN, Kenny DT, Tattersall MH. Communicating prognosis in early breast cancer: do women understand the language used? Med J Aust 1999; 171: 290-294.

84 Chapman K, Abraham C, Jenkins V, Fallowfield L. Lay understanding of terms used in cancer consultations. Psychooncology 2003; 12: 557-566.

85 Hargie O, Marshall P. Interpersonal communication: a theoretical framework. In: Hargie O, editor. A handbook of communication skills. London: Routledge, 1986.

86 Humphrey GB, Littlewood JL, Kamps WA. Physician/patient communication: a model considering the interaction of physicians' therapeutic strategy and patients' coping style. J Cancer Educ 1992; 7: 147-152.

87 Fallowfield L. Participation of patients in decisions about treatment for cancer. BMJ 2001; 323: 1144.

88 Gattellari M, Voigt KJ, Butow PN, Tattersall MH. When the treatment goal is not cure: are cancer patients equipped to make informed decisions? J Clin Oncol 2002; 20: 503-513.

89 Lofmark R, Nilstun T. Not if, but how: one way to talk with patients about forgoing life support. Postgrad Med J 2000; 76: 26-28.

90 Iconomou G, Viha A, Koutras A, et al. Information needs and awareness of diagnosis in patients with cancer receiving chemotherapy: a report from Greece. Palliat Med 2002; 16: 315-321.

91 Johnston G, Abraham C. Managing awareness: negotiating and coping with a terminal prognosis. Int J Palliat Nurs 2000; 6: 485-494.

92 Kai I, Ohi G, Yano E, et al. Communication between patients and physicians about terminal care: a survey in Japan. Soc Sci Med 1993; 36: 1151-1159.

93 Addington-Hall J, McCarthy M. Dying from cancer: results of a national population-based investigation. Palliat Med 1995; 9: 295-305

94 Mouton C, Teno JM, Mor V, Piette J. Communication of preferences for care among human immunodeficiency virus-infected patients. Barriers to informed decisions? Arch Fam Med 1997; 6: 342-347.

95 Kaplowitz SA, Campo S, Chiu WT. Cancer patients' desires for communication of prognosis information. Health Commun 2002; 14: 221-241.

96 Chochinov HM, Hack T, Hassard T, et al. Dignity in the terminally ill: a cross-sectional, cohort study. Lancet 2002; 360: 2026-2030.

97 Delvecchio Good MJ, Good BJ, Schaffer C, et al. American oncology and the discourse on hope. Cult Med Psychiatry 1990; 14: 59-79.

98 Carter PA. A not-so-silent cry for help. Older female cancer caregivers' need for information. J Holist Nurs 2001; 19: 271-284.

99 Cutcliffe JR. How do nurses inspire and instil hope in terminally ill HIV patients? J Adv Nurs 1995; 22: 888-895.

100 Flemming $\mathrm{K}$. The meaning of hope to palliative care cancer patients. Int J Palliat Nurs 1997; 3: 14-18.

101 Meredith C, Symonds P, Webster L, et al. Information needs of cancer patients in west Scotland: cross sectional survey of patients' views. BMJ 1996; 313: 724-726.

102 Baile WF, Buckman R, Lenzi R, et al. SPIKES - a six-step protocol for delivering bad news: application to the patient with cancer. Oncologist 2000; 5: 302-311.

103 Back AL, Arnold RM, Baile WF, et al. Approaching difficult communication tasks in oncology. CA Cancer J Clin 2005; 55: 164-177.

104 Clover A, Browne J, McErlain P, Vandenberg B. Patient approaches to clinical conversations in the palliative care setting. J Adv Nurs 2004; 48: 333-341.

105 Dowsett SM, Saul JL, Butow PN, et al. Communication styles in the cancer consultation: preferences for a patient-centred approach. Psychooncology 2000; 9: 147-156.

106 Gattellari M, Butow PN, Tattersall MH. Sharing decisions in cancer care. Soc Sci Med 2001; 52: 1865-1878. 


\section{COMMUNICATING PROGNOSIS AND END-OF-LIFE ISSUES}

107 Fischer GS, Tulsky JA, Arnold RM. Communicating a poor prognosis. In: Portenoy RK, Bruera E, editors. Topics in palliative care. New York: Oxford University Press, 2000.

108 Friedrichsen MJ, Strang PM, Carlsson ME. Cancer patients' interpretations of verbal expressions when given information about ending cancer treatment. Palliat Med 2002; 16: 323-330.

109 Baile WF, Beale EA. Giving bad news to cancer patients: matching process and content. J Clin Oncol 2001; 19: 2575-2577.

110 Palliative Care Australia. A guide to palliative care service development: a population approach. Canberra: Palliative Care Australia, 2005. http:// www.pallcare.org.au/Default.aspx?tabid=1221 (accessed May 2007).

111 Weissman DE, Griffie J. The palliative care consultation service of the medical college of Wisconsin. J Pain Symptom Manage 1994; 9: 474479.

112 World Health Organization. National cancer control guidelines: policies and managerial guidelines. Geneva: WHO, 2002.

113 Palliative Care Australia. Standards for providing quality palliative care for all Australians. Canberra: Palliative Care Australia, 2005. http:// www.pallcare.org.au/Default.aspx?tabid=1221 (accessed May 2007).

114 Hearn J, Higginson I. Do specialist palliative care teams improve outcomes for cancer patients? A systematic literature review. Palliat Med 1998; 12: 317-332.

115 Stockler M, Tattersall M, Boyer M, et al. Disarming the guarded prognosis: predicting survival in newly referred patients with incurable cancer. Br J Cancer 2006; 94: 208-212.

116 Christakis N. Death foretold: prophecy and prognosis in medical care. Chicago: University of Chicago Press, 1999.

117 Lamont EB, Christakis NA. Complexities in prognostication in advanced cancer: "to help them live their lives the way they want to". JAMA 2003; 290: 98-104.

118 Glare P. Prognosis in palliative care: ten common questions. Prog Palliat Care 2004; 12: 10-15.

119 Fukui S. Information needs and the related variables of Japanese family caregivers of terminally ill cancer patients. Nurs Health Sci 2004; 6: 2936.

120 Emanuel LL, von Gunten CF, Ferris FD, editors. Advance care planning. In: The Education for Physicians on End-of-life Care (EPEC) curriculum. Chicago: The Robert Wood Johnson Foundation, 1999.

121 Roter DL, Larson S, Fischer GS, et al. Experts practice what they preach: a descriptive study of best and normative practices in end-of-life discussions. Arch Intern Med 2000; 160: 3477-3485.

122 NSW Health. Using advance care directives: New South Wales. Sydney: NSW Health, 2004. http://www.health.nsw.gov.au/policies/gl/2005/ GL2005_056.html (accessed May 2007).

123 Tulsky JA, Chesney MA, Lo B. See one, do one, teach one? House staff experience discussing do-not-resuscitate orders. Arch Intern Med 1996; 156: $1285-1289$

124 Molloy W. Let me decide: why we all need a living will. Canada: Penguin Group, 2005.

125 Golin CE, Wenger NS, Liu H, et al. A prospective study of patientphysician communication about resuscitation. J Am Geriatr Soc 2000; 48 (5 Suppl): S52-S60.

126 Martin DK, Emanuel LL, Singer PA. Planning for the end of life. Lancet 2000; 356: 1672-1676.

127 NSW Health. Guidelines for end-of-life care and decision-making. Sydney: NSW Health, 2005. http://www.health.nsw.gov.au/pubs/2005/ endlifecare.html (accessed May 2007).

128 Emanuel LL, von Gunten CF, Ferris FD, editors. Withholding, withdrawing therapy. In: The Education for Physicians on End-of-life Care (EPEC) curriculum. Chicago: The Robert Wood Johnson Foundation, 1999.

129 Dexter PR, Wolinsky FD, Gramelspacher GP, et al. Effectiveness of computer-generated reminders for increasing discussions about advance directives and completion of advance directive forms. A randomized, controlled trial. Ann Intern Med 1998; 128: 102-110.

130 Biegler P, Stewart C, Savulescu J, Skene L. Determining the validity of advance directives. Med J Aust 2000; 172: 545-548.

131 Patel R, Sinuf T, Cook D. Influencing advance directive completion rates in non-terminally ill patients: a systematic review. J Crit Care 2004; 19: 19.

132 Fagerlin A, Schneider C. Enough: the failure of the living will. Hastings Cent Rep 2004; 34: 30-42.

133 Lo B, Steinbrook R. Resuscitating advance directives. Arch Intern Med 2004; 164: 1501-1506.
134 Teno J, Licks S, Lynn J, et al. Do advance directives provide instructions that direct care? SUPPORT investigators. Study to Understand Prognoses and Preferences for Outcomes and Risks of Treatment. J Am Geriatr Soc 1997; 45: 508-512.

135 Hammes B, Rooney B. Death and end-of-life planning in one Midwestern community. Arch Intern Med 1998; 158: 383-390.

136 Prendergast T. Advance care planning: Pitfalls, progress, promise. Crit Care Med 2001; 29 (2 Suppl): N34-N39.

137 Demoratz MJ. Advance directives: getting patients to complete them before they need them. Case Manager 2005; 16: 61-63.

138 Doyal L, Wilsher D. Withholding cardiopulmonary resuscitation: proposals for formal guidelines. BMJ 1993; 306: 1593-1596.

139 Emanuel LL, von Gunten CF, Ferris FD, eds. Medical futility. In: The Education of Physicians on End-of-life Care (EPEC) curriculum. Chicago: The Robert Wood Johnson Foundation, 1999.

140 Quill TE. Perspectives on care at the close of life. Initiating end-of-life discussions with seriously ill patients: addressing the "elephant in the room". JAMA 2000; 284: 2502-2507.

141 Ewer MS, Kish SK, Martin CG, et al. Characteristics of cardiac arrest in cancer patients as a predictor of survival after cardiopulmonary resuscitation. Cancer 2001; 92: 1905-1912.

142 Bedell S, Pelle D, Maher P, Cleary P. Do-not-resuscitate orders for critically-ill patients in the hospital: how are they used and what is their impact? JAMA 1986; 256: 233-237.

143 Peatfield R, Sillett R, Taylor D, McNicol M. Survival after cardiac arrest in hospital. Lancet 1977; 1: 1223-1225.

144 Manisty C, Waxman J. Doctors should not discuss resuscitation with terminally ill patients: FOR. BMJ 2003; 327: 614-615.

145 Dugan DO, Gluck EH. Discussing life-sustaining treatments: an overview and communications guide for primary care physicians. Compr Ther 2004; 30: 25-36.

146 British Medical Association. Decisions relating to cardiopulmonary resuscitation. A joint statement from the British Medical Association, the Resuscitation Council (UK), and the Royal College of Nursing. London: BMA, 2002. http://www.bma.org.uk/ap.nsf/Content/cardioresus (accessed May 2007).

147 National Council for Hospice and Specialist Palliative Care Services and the Association for Palliative Medicine. Ethical decision making in palliative care: cardiopulmonary resuscitation for people who are terminally ill. J R Coll Physicians Edinb 2002; 32: 280.

148 Australian Medical Association. Care of severely and terminally ill patients - 1997 [position statement]. Sydney: AMA, 1997. http:// www.ama.com.au/web.nsf/doc/SHED-5FK3DB (accessed May 2007).

149 Consent to Medical Treatment and Palliative Care Act 1995 (SA).

150 Stewart C. Medical futility. In: Albrecht G, editor. Encyclopedia of disability. Thousand Oaks, Calif: SAGE Publications, 2005.

151 Eliott JA, Olver IN. Legitimating do-not-resuscitate orders: a discursive study of cancer patients' speech. J Palliat Care 2003; 19: 100-106.

152 Olver I, Eliott J, Blake-Mortimer J. Cancer patients' perceptions of do not resuscitate orders. Psychooncology 2002; 11: 181-187.

153 Kerridge I, Myser C, Mitchell K, Hamblin J. Guidelines for no-CPR orders. Med J Aust 1994; 161: 270-272.

154 Luce JM. Physicians do not have a responsibility to provide futile or unreasonable care if a patient or family insists. Crit Care Med 1995; 23: 760-766.

155 Dunphy K. Futilitarianism: knowing how much is enough in end-of-life health care. Palliat Med 2000; 14: 313-322.

156 Teno JM, Stevens M, Spernak S, Lynn J. Role of written advance directives in decision making: insights from qualitative and quantitative data. J Gen Intern Med 1998; 13: 439-446.

157 National Breast Cancer Centre and National Cancer Control Initiative. Clinical practice guidelines for the psychosocial care of adults with cancer. Canberra: NHMRC, 2003. http://www.nhmrc.gov.au/publications/synopses/cp90syn.htm (accessed May 2007).

158 Pitorak EF. Learning to have difficult conversations leads to increased hospice referrals. Home Healthc Nurse 2003; 21: 629-632.

159 Karlawish JH, Quill T, Meier DE. A consensus-based approach to providing palliative care to patients who lack decision-making capacity: ACP-ASIM End-of-Life Care Consensus Panel. Ann Intern Med 1999; 130: 835-840.

160 Emanuel LL, von Gunten CF, Ferris FD. Advance care planning. Arch Fam Med 2000; 9: 1181-1187.

161 Lawton S, Carroll D. Communication skills and district nurses: examples in palliative care. Br J Community Nurs 2005; 10: 134-136. 


\section{CLINICAL PRACTICE GUIDELINES}

162 Akabayashi A, Fetters MD, Elwyn TS. Family consent, communication, and advance directives for cancer disclosure: a Japanese case and discussion. J Med Ethics 1999; 25: 296-301.

163 Hudson PL, Aranda S, Kristjanson LJ. Meeting the supportive needs of family caregivers in palliative care: challenges for health professionals. J Palliat Med 2004; 7: 19-25.

164 Henman M, Butow P, Brown R, et al. Lay constructions of decision making in cancer care. Psychooncology 2002; 11: 295-306.

165 Rousseau P. The art of oncology: when the tumor is not the target. Death denial. J Clin Oncol 2000; 18: 3998-3999.
166 Meier DE, Back AL, Morrison RS. The inner life of physicians and care of the seriously ill. JAMA 2001; 286: 3007-3014.

167 Turner J, Kelly B. The concept of debriefing and its application to staff dealing with life-threatening illnesses such as cancer, AIDS and other conditions. In: Raphael B, Wilson JP, editors. Psychological debriefing: theory, practice and evidence. Cambridge: Cambridge University Press, 2000.

(Received 16 Nov 2006, accepted 18 Mar 2007) 